\title{
Recent Advances in the Palladium Catalyzed Suzuki-Miyaura Cross-Coupling Reaction in Water
}

\author{
Anamitra Chatterjee, ${ }^{[\mathrm{a}]}$ and Thomas R. Ward*[a]
}

Department of Chemistry, University of Basel, Spitalstrasse 51, CH-4056 Basel, Switzerland

\section{Graphical Abstract}

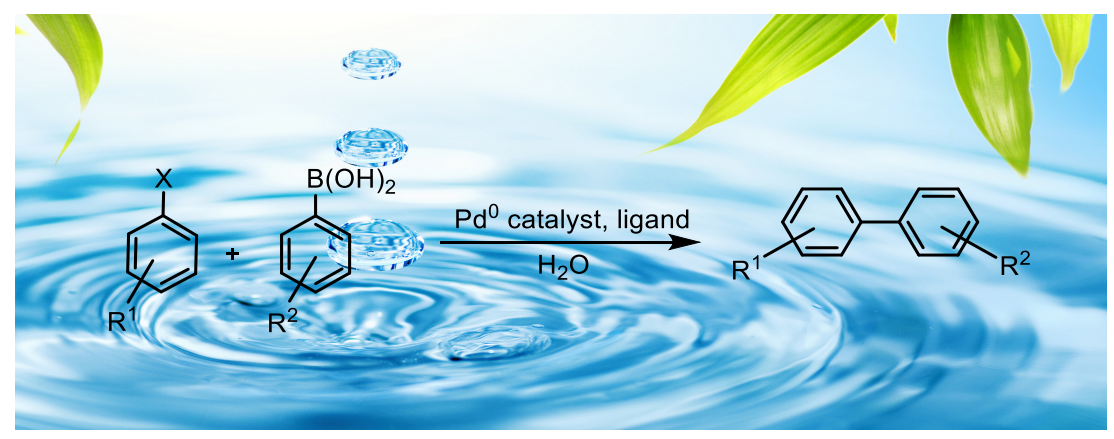

\begin{abstract}
The palladium-catalyzed Suzuki-Miyaura cross-coupling reaction of organic halides with boronic acids is one of the most versatile methods for the synthesis of biaryls. Green chemistry is a rapidly developing new field that provides us a proactive avenue for the sustainable development of future science and technologies. When designed properly, clean chemical technology can be developed in water as a reaction medium. The technologies generated from such green chemistry endeavors may often be cheaper and more profitable. This review covers the literature on palladium-catalysed the Suzuki-Miyaura cross-coupling reaction in water.
\end{abstract}

Keywords: Cross-coupling, Palladium, Aqueous catalysis, Green chemistry, Sustainable chemistry

${ }^{[a]}$ Dpt. Chemistry, University of Basel, Spitalstrasse 51, CH-4056 Basel, Switzerland e-mail: thomas.ward@unibas.ch 


\section{Introduction}

The Suzuki-Miyaura cross-coupling reaction (SMC hereafter) is one of the most important synthetic transformations developed in the $20^{\text {th }}$ century. $[1,2]$ This is one of the most versatile methods for the synthesis of biaryls and alkene derivatives. These are structural constituents of numerous agrochemicals, natural products, pharmaceuticals, and polymers.[2-5] Several reviews on the SMC have been published in the literature.[6-11] Recently, green chemistry awareness attempts to address the environmental impact of both chemical products and the processes by which these are produced.[12,13] Around $80 \%$ of the chemical waste from a reaction mixture corresponds to the solvent. Water is commonly considered as a benign solvent in view of its non-toxicity and abundant natural occurrence. The use and release of "clean water" will have the least impact to the environment.[14] In the case of the SMC, the stability of boronic acids in aqueous solvent are viewed as advantageous compared to other cross-coupling reactions to be performed in water. The literature on the SMC in water up to 2010 has been reviewed by Polshettiwar et al.[15] Herein, we focus on the use of water as a medium for SMC in homogeneous and heterogeneous systems. This review covers the period from 2011 up to August 2015. Current challenges of palladium catalysed SMC in water include a) the reactivity with lowcost aryl chlorides, b) low catalyst loading, c) the functional group tolerance and d) mild reaction conditions. To address these challenges, several groups developed palladium-catalysed SMC in water with either homogenous- or heterogeneous systems. 


\section{Homogeneous SMC in Water}

\subsection{P-donors Ligands}

Because of the undesired decomposition of $P$-donors ligands, their use for aqueous SMC has remained limited compared to $\mathrm{N}$-donor and NHC ligands. A handful example are found in the recent literature.

For example, $\mathrm{Yu}$ and co-workers reported SMC in water catalyzed by a supramolecular assembly held together with noncovalent interactions in the presence of palladium (Scheme 1).[16] For this purpose, they designed the tridentate ligand Phenylphosphinacalix[3]trifuran 1. In the presence of palladium acetate, the resulting catalyst proved extremely active with turnover numbers as high as $3.05 \times 10^{7}$ with $2 \times 10^{-8} \mathrm{~mol} \%$ Pd loading. The author suggested that these high TONs are not due to a facilitated oxidative addition step but the longevity of the catalyst may be a key to reach high TONs.
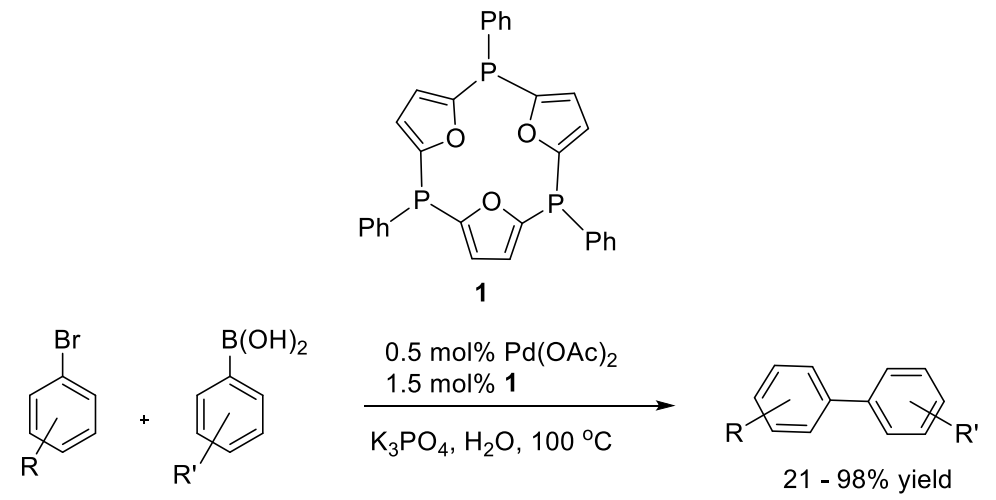

$$
\begin{aligned}
\mathrm{X}= & \mathrm{Cl}, \mathrm{Br} \\
\mathrm{R}= & \mathrm{H}, \mathrm{Me}, \mathrm{OMe}, \mathrm{COMe} \\
& \mathrm{NO}_{2}, \mathrm{NH}_{2} \\
\mathrm{R}^{\prime}= & \mathrm{H}, \mathrm{OMe}, \mathrm{Me}
\end{aligned}
$$

Scheme 1 Phenylphosphinacalix[3]trifuran 1 as an efficient ligand for the SMC in

$$
\text { water.[16] }
$$


An efficient and recyclable protocol for the SMC in water was reported by Liu et al. based on the cloud point (Cp) of the thermoregulated ligand 2 (Scheme 2).[17] The palladium catalyst remains in the aqueous phase at lower temperature $\left(<\mathrm{Cp}, 93^{\circ} \mathrm{C}\right)$ but transfers into the substrate phase at higher temperature $\left(>\mathrm{Cp}, 93^{\circ} \mathrm{C}\right)$. This method allowed the preparation of a variety of biaryls in high yields (up to 99\%) with 0.05 mol\% Pd loading. The catalytic system can be recycled four times with high efficiency.

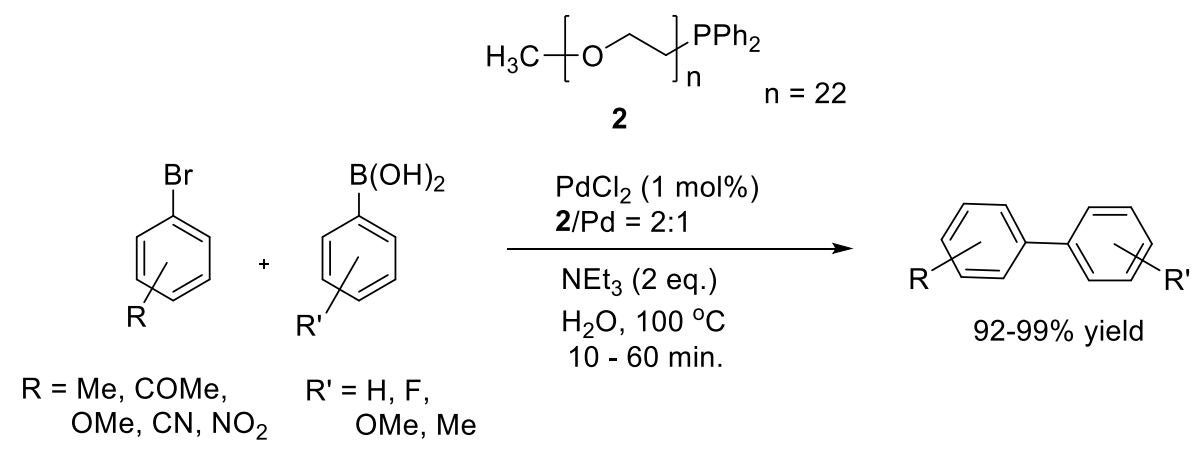

Scheme 2 A thermoregulated catalytic system for the SMC in water.[17]

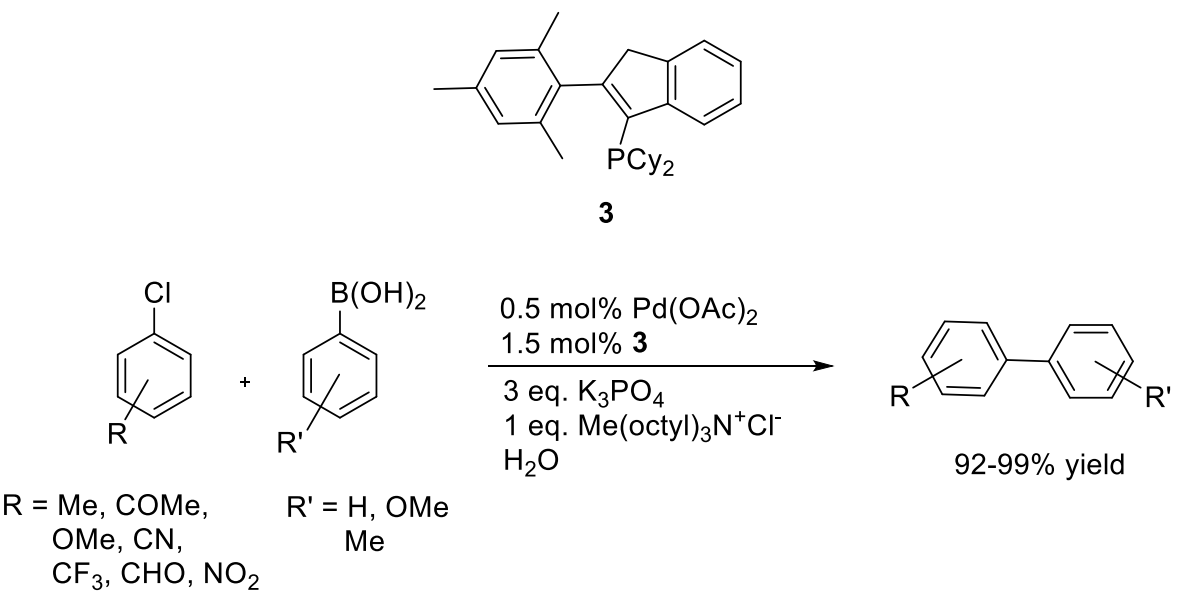

Scheme 3 Bulky monophosphine ligand for the SMC in water developed by Liu and co-workers.[18] 
Recently, Liu and co-workers[18] reported a catalytic system consisting of the (2mesitylindenyl)dicyclohexylphosphine ligand 3 in combination with $\left[\mathrm{Pd}(\mathrm{OAc})_{2}\right]$ and $\left[\mathrm{Me}(\text { octyl })_{3} \mathrm{~N}^{+} \mathrm{Cl}^{-}\right.$as the phase-transfer reagent. The resulting systems displayed high catalytic activity in the SMC of various aryl- and heteroaryl chlorides in water (Scheme 3).

More recently, Eppinger and co-workers used the palladacycle 4, under air and at room temperature, for the coupling of aryl iodides and bromides with a variety of boronic acids.[19] The biaryl products were obtained in excellent yields (up to 99\%) with $0.02 \mathrm{~mol} \%$ catalyst loading (Scheme 4). Poisoning experiments support the hypothesis of the homogenous nature of the catalytically active species, although the pre-catalyst $\mathbf{4}$ is insoluble in water.

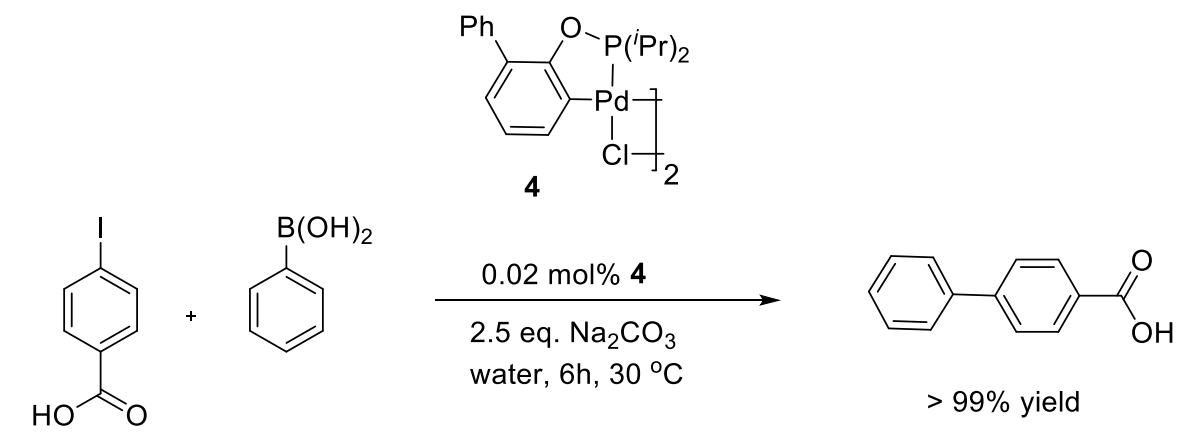

Scheme 4 Palladacycle 4 for SMC in water developed by Eppinger and coworkers.[19]

Later Gröger and co-workers reported the combination of a palladium-catalyzed SMC in aqueous medium with an enzymatic reduction in a one-pot process at room temperature.[20, 21] For the SMC, a water-soluble palladium catalyst was prepared from palladium chloride and TPPTS $($ TPPTS $=$ tris(3-sulfonatophenyl)phosphine 
hydrate, sodium salt). After completion of the reaction and adjustment of the $\mathrm{pH}$ to 7.0, the biaryl ketone product was reduced in situ via alcohol dehydrogenase (ADH). The desired biarylalcohol 5 was produced in up to $>95 \%$ conversion (over the two steps) and excellent enantioselectivities ( $>99 \%$ ee) (Scheme 5).

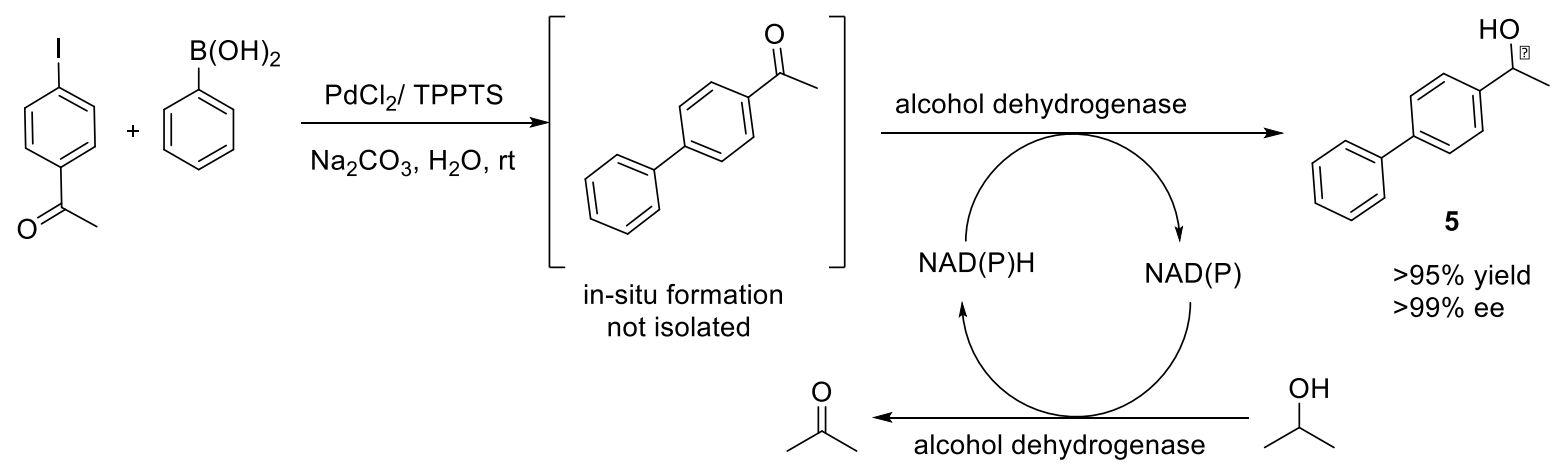

Scheme $5 \mathrm{SMC}$ and subsequent enzymatic reduction for the synthesis of chiral biarylalcohols in water.[20]

In an independent study, zwitterionic palladium complexes were reported by Lee and co-workers for the SMC in water.[22] The zwitterionic phosphine complex 6 was efficient in catalyzing the SMC of sterically hindered aryl chlorides and arylboronic acids in dioxane/water (4:1) or neat water at room temperature (Scheme 6).
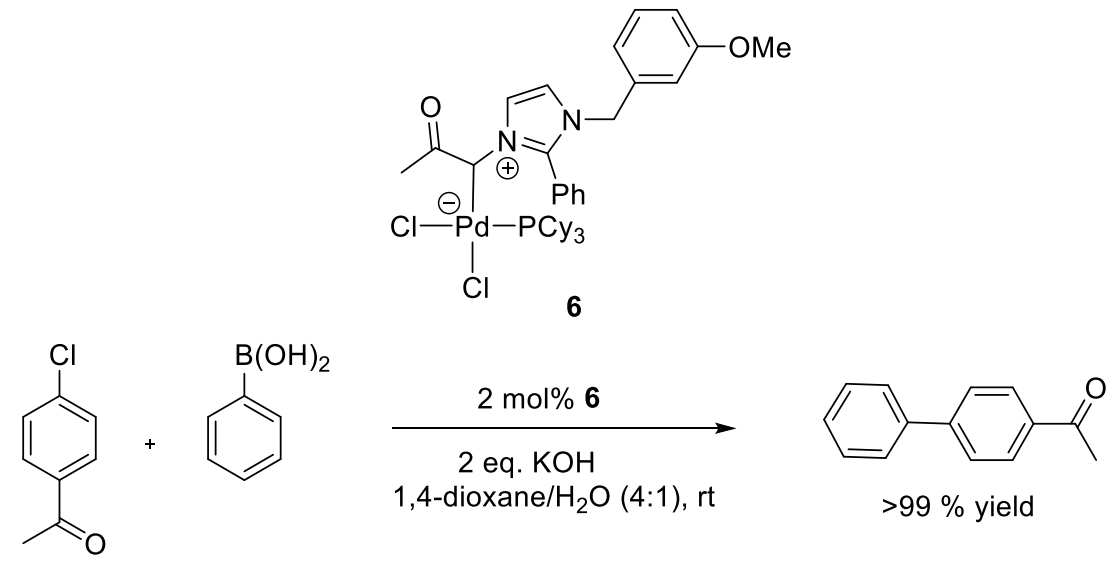

Scheme 6 A zwitterionic palladium complexe 6 for the SMC in water.[22] 
In a very recent study, Khazalpour and co-workers reported the palladium-phosphine system 7 as an active and recyclable pre-catalyst for SMC in water.[23] A fivemembered chelate ring is formed upon coordination of the ligand through the phosphine and the ylidic carbon atom. The catalytic system could be reused four times without significant loss of activity (Scheme 7).
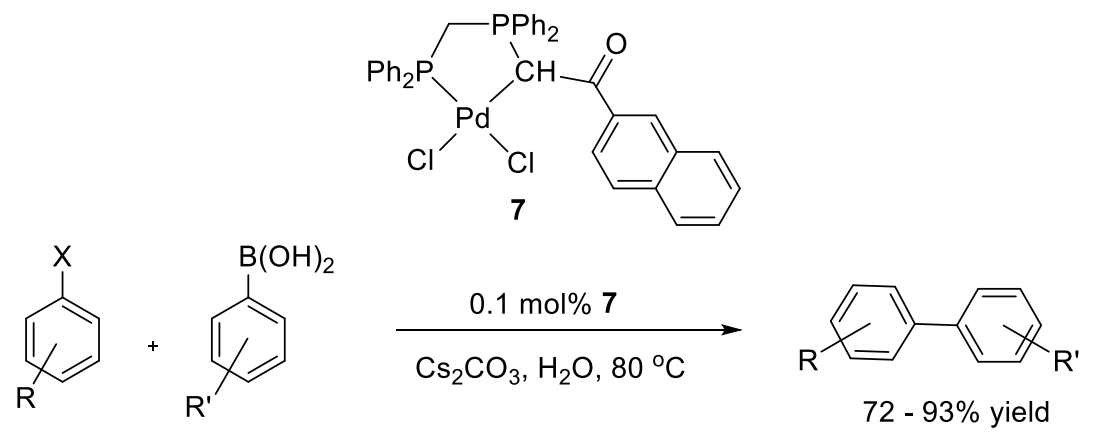

$$
\begin{aligned}
X= & \mathrm{Cl}, \mathrm{Br}, \mathrm{I} \\
\mathrm{R}= & \mathrm{H}, \mathrm{Me}, \mathrm{COMe}, \\
& \mathrm{OMe}, \mathrm{CHO}^{\mathrm{NO}_{2}} \\
\mathrm{R}^{\prime}= & \mathrm{H}, \mathrm{CH}_{2} \mathrm{CH}_{3}
\end{aligned}
$$

Scheme 7 A palladium-phosphine catalytic system 7 for SMC in water developed by

$$
\text { Khazalpour and co-workers.[23] }
$$

\subsection{N-donor Ligands}

Although $N$-donor ligands have been widely neglected in homogeneous organometallic catalysis,[24] there has been a resurgence of interest for $\mathrm{N}$-donor ligands in SMC. Various types of $N$-donor ligands are presented below: i) pyridines/imines, ii) imidates iii) pyrimidines iv) amines v) orthometallated palladacycles vi) amides and vii) hydrazones. 


\section{i) Pyridines/imines:}

Planas and co-workers developed $o$ - and $m$-carborane-based NBN pincer palladium complexes for SMC in water. These catalyst require remarkably low catalyst loadings $\left(10^{-4} \mathrm{mmol} \%\right)$ and display good functional group tolerance.[25] They used an NBN pincer complex instead of an NCN pincer complex because of the stronger electron donating ability of the boron moiety which exhibited stronger trans-influence. Complex (o-CB-L1)Pd 8 displayed a better catalytic profile than $(\boldsymbol{m}-\mathbf{C B}-\mathbf{L} 1) \mathbf{P d} 9$ and with excellent conversions and TON values ranging from $770^{\prime} 000$ to $990^{\prime} 000$ (Scheme 8). Although potentially chiral, no mention is made on whether the ligands were used as a racemate, in their meso-form or in enantiopure form.

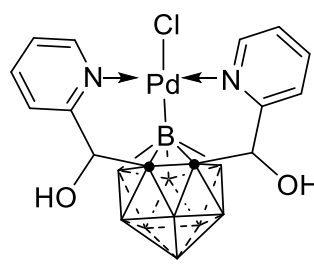

(o-CB-L1)Pd

8

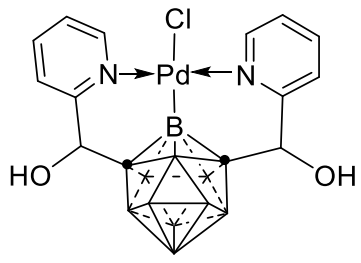

(m-CB-L1)Pd

9

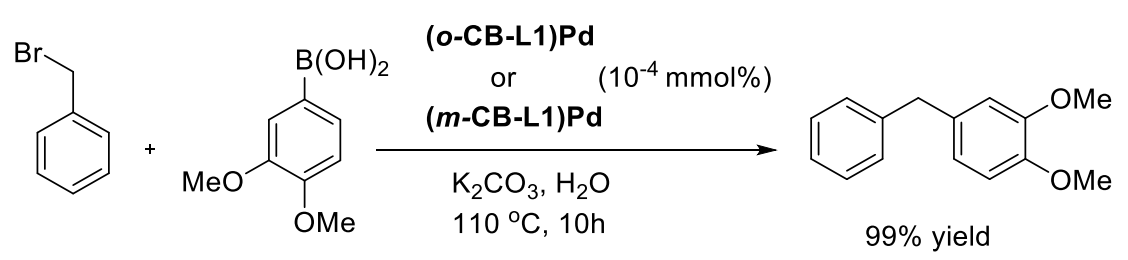

Scheme $8 \mathrm{SMC}$ in water with $o$ - and $m$-carborane-based NBN pincer palladium complexes.[25]

A set of water soluble pincer pyridine-diamine ligands 10, 11 was developed by the Morales group for the SMC (Scheme 9). The presence of hydroxy-groups on the ligand ensures water solubility. Excellent yields were achieved $(950 \mathrm{TON})$ for the 
formation of biphenyls at $95^{\circ} \mathrm{C}$ in pure water.[26] Purification is readily achieved by decantation as the product is insoluble in water. The easy synthesis of the ligand from commercial starting materials, combined with the high catalytic activity of the corresponding complex deserves particular mention.

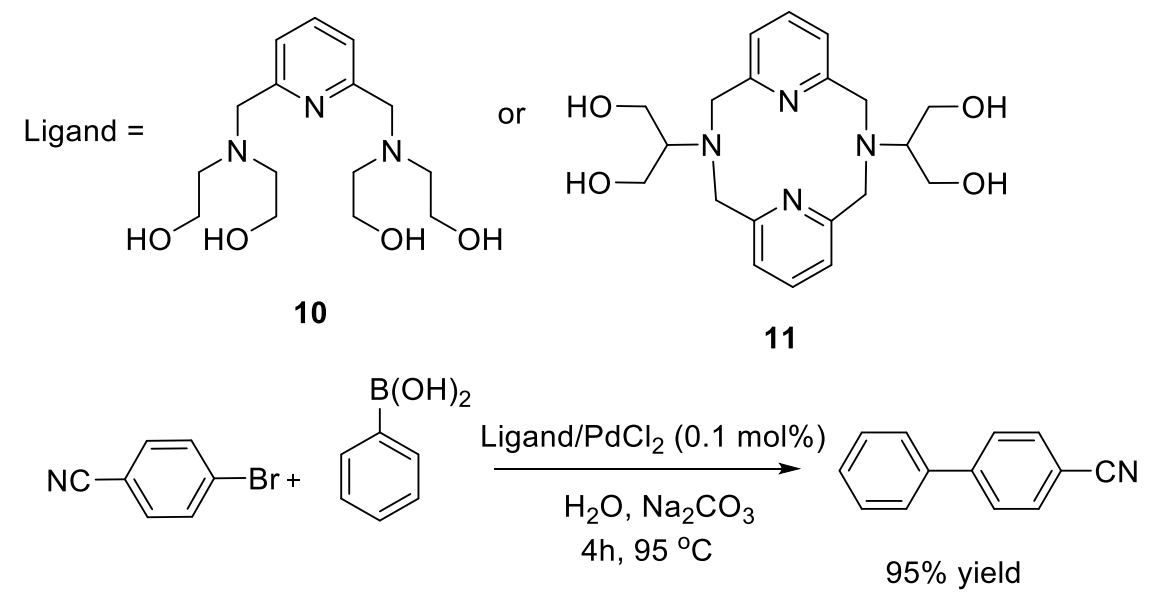

Scheme 9 SMC in water with water soluble pincer palladium complexes derived from ligand 10 or 11.[26]

Recently, $\mathrm{Tu}$ and co-workers reported a hydrophilic pyridine-bridged bisbenzimidazolylidene palladium pincer complex $\mathbf{1 2}$ which is a highly efficient catalyst towards the SMC in water (Scheme 10).[27]
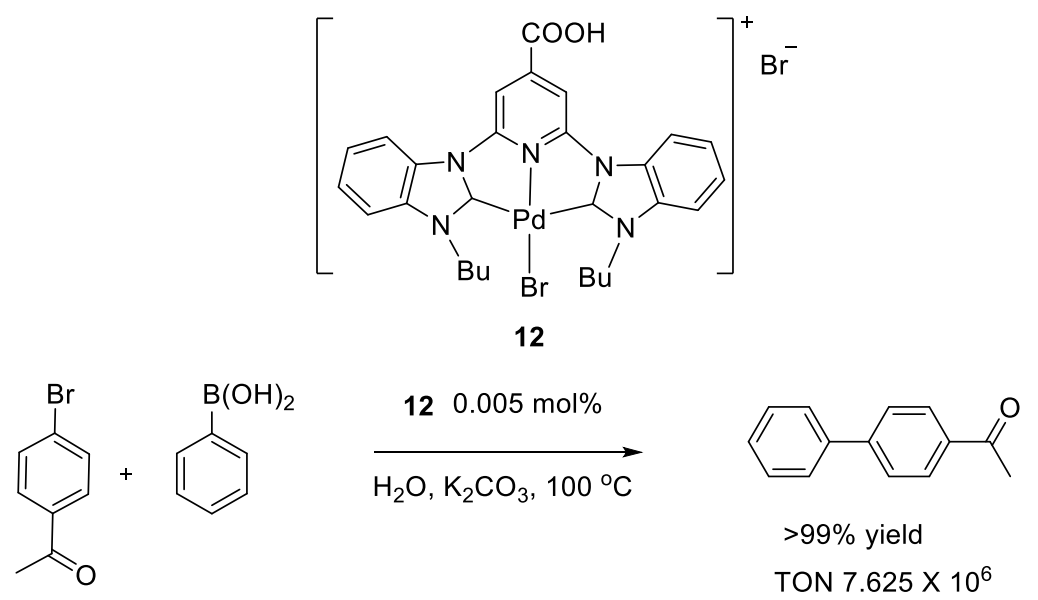
Scheme 10 Palladium-pincer complex 12 for the SMC in water.[27]

The $\mathrm{Pd}(\mathrm{OAc})_{2}-(\mathrm{DHQD})_{2} \mathrm{PHAL} 13$ catalyzed SMC was reported by Saikia and coworkers (Scheme 11). This is a very simple, mild and efficient protocol for the synthesis of biaryls/heterobiaryls in neat $\mathrm{H}_{2} \mathrm{O}$ at room temperature. Furthermore, the catalyst system is recyclable and can be employed in several consecutive runs without significant loss in catalytic activity.[28] No mention was made concerning the enantioselective SMC with this system.
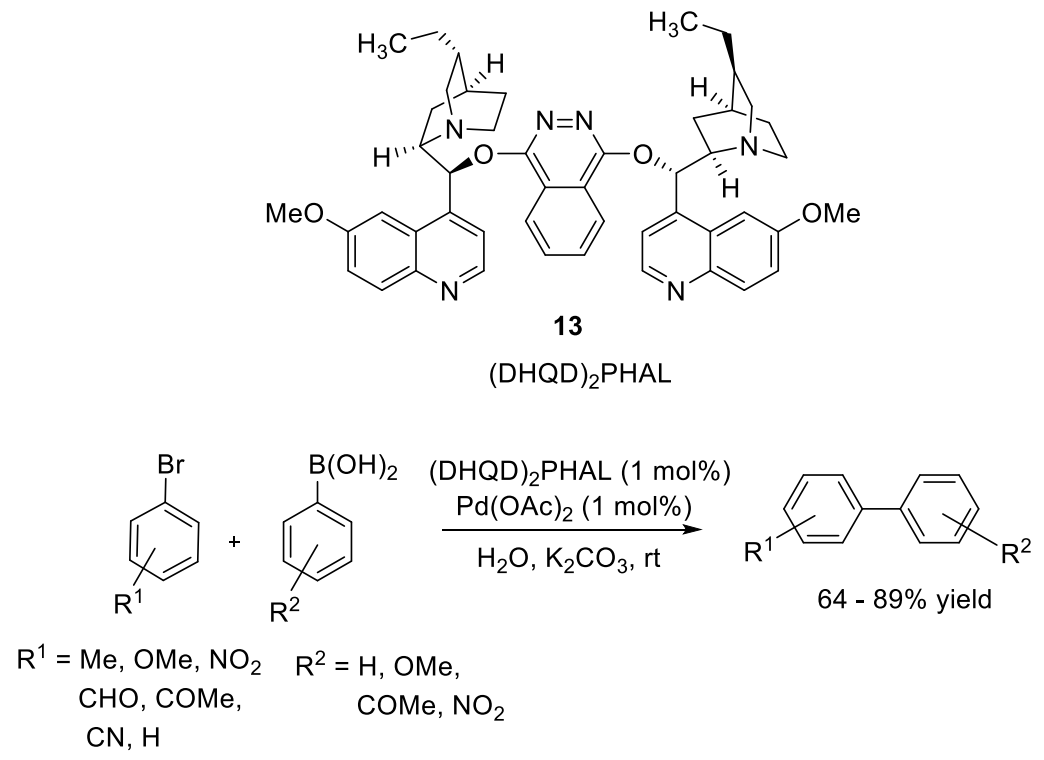

Scheme $11 \mathrm{Pd}(\mathrm{OAc})_{2}-(\mathrm{DHQD})_{2} \mathrm{PHAL} 13$ catalyzed SMC in water.[28] (DHQD) ${ }_{2}$ PHAL = Hydroquinidine 1,4-phthalazinediyl diether.

Wang and coworkers reported the synthesis of the palladium chelating complex 14 and its application for the SMC in air and water (Scheme 12).[29] The biaryl products were obtained in good to excellent yields with $0.1 \mathrm{~mol} \%$ catalyst loading. 


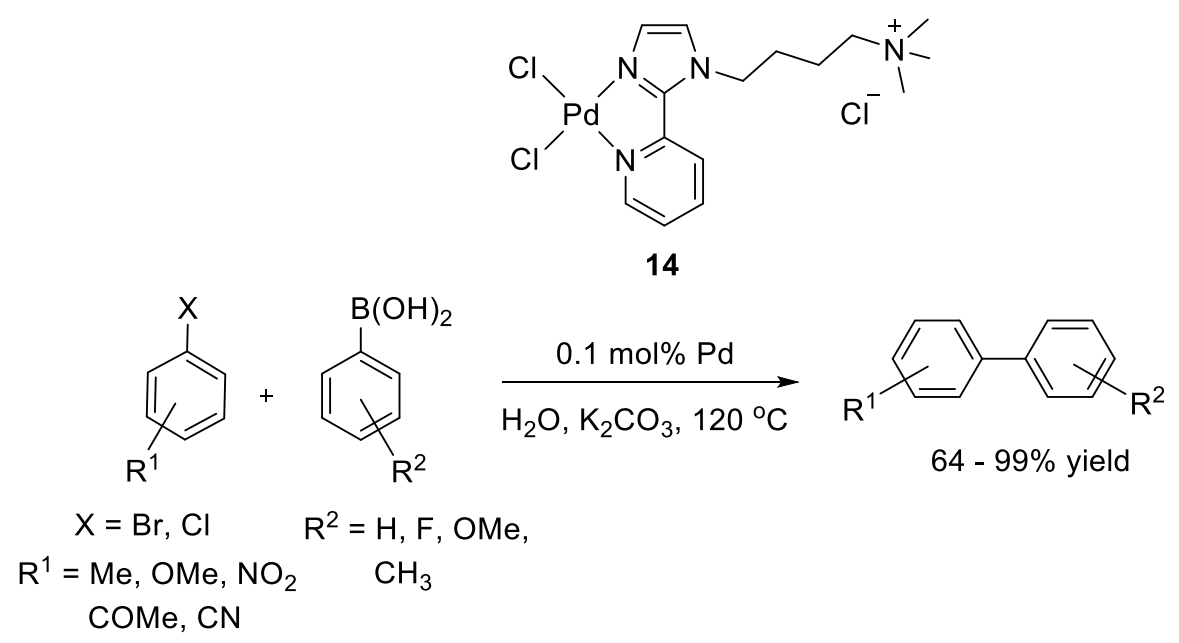

Scheme 12 Palladium chelating complex 14 for SMC in water developed by Wang and coworkers.[29]

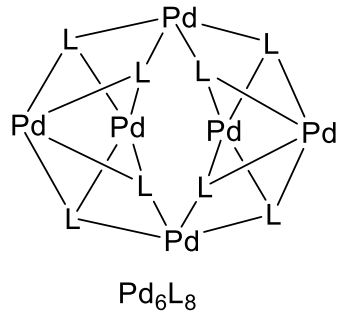

15
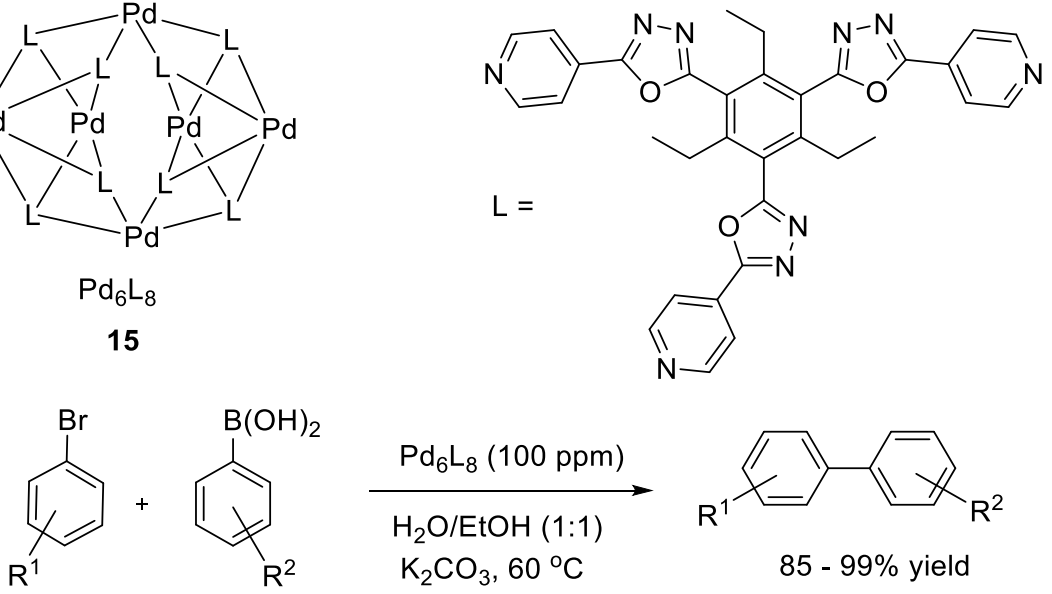

$\mathrm{R}^{1}=\mathrm{Me}, \mathrm{OMe}, \mathrm{NO}_{2} \quad \mathrm{R}^{2}=\mathrm{H}, \mathrm{OMe}$,

COMe, $\mathrm{CN}, \mathrm{H}$, $\mathrm{CHO}$

$\mathrm{CHO}, \mathrm{Py}$

Scheme 13 A self-assembled $\mathrm{Pd}_{6} \mathrm{~L}_{8}$ cluster 15 for the SMC in water developed by

Dong.[30] 
A self-assembled hexanuclear cluster $\mathrm{Pd}_{6} \mathrm{~L}_{8} 15$ ( $\mathrm{L}=1,3,5$-tris(4'-pyrirdyloxadiazol)2,4,6-triethylbenzene) was reported by Dong for the SMC at very low catalyst loadings (i.e.100 ppm) (Scheme 13).[30] Depending on the solvent used for the SMC, the system was either homogeneous or heterogeneous: the reaction was homogeneous in water-ethanol whereas it was heterogeous in xylene.

Senemoglu reported a microwave-assisted aqueous SMC catalyzed by unsymmetrical sulfonated water-soluble Pd(II)-pyridylimine complexes 16 (Scheme 14).[31] The compounds proved to be effective catalysts with up to $980 \mathrm{TON}$.

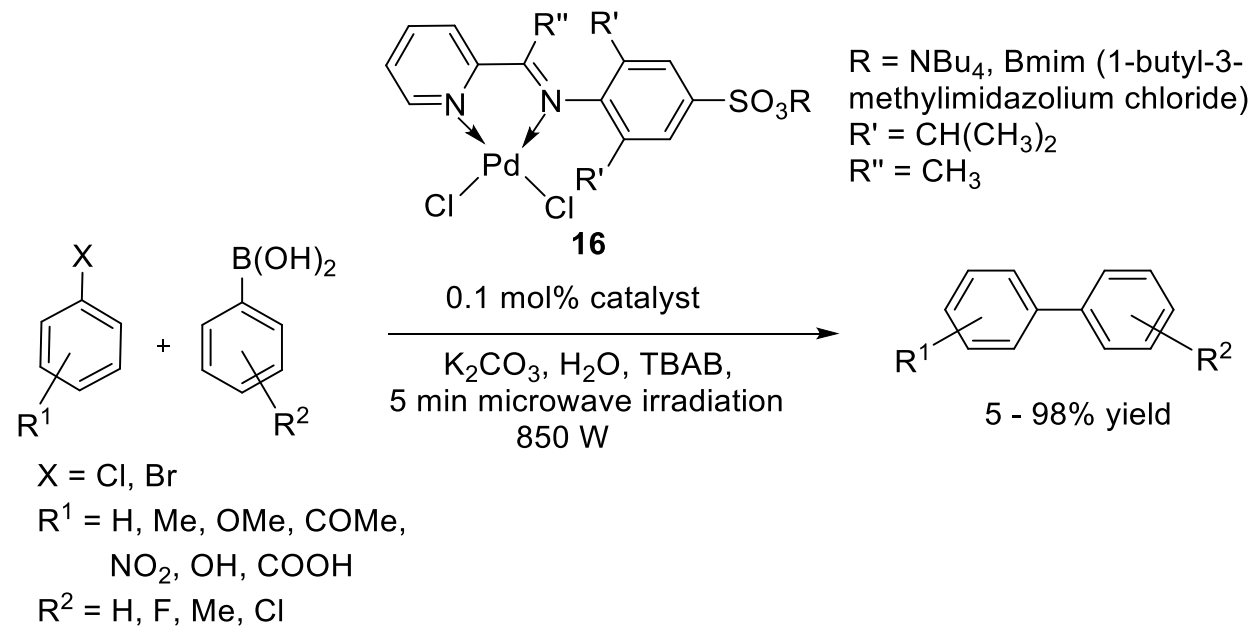

Scheme 14 Unsymmetrical sulfonated water-soluble Pd(II)-pyridyl imine complexes for SMC in water.[31]

Recently, Hor and Young reported a supramolecular recyclable catalyst for the aqueous SMC (Scheme 15).[32] Upon host-guest incorporation of 17 within heptakis(2,6-di- $O$-methyl)- $\beta$-CD 18 in aqueous media, a water soluble supramolecular 
assembly 19 was generated. This catalyst $19(0.5 \mathrm{~mol} \%)$ efficiently catalyzed the SMC ( $>97 \%$ yield) between hydrophilic aryl bromides with aryl boronic acid at room temperature.

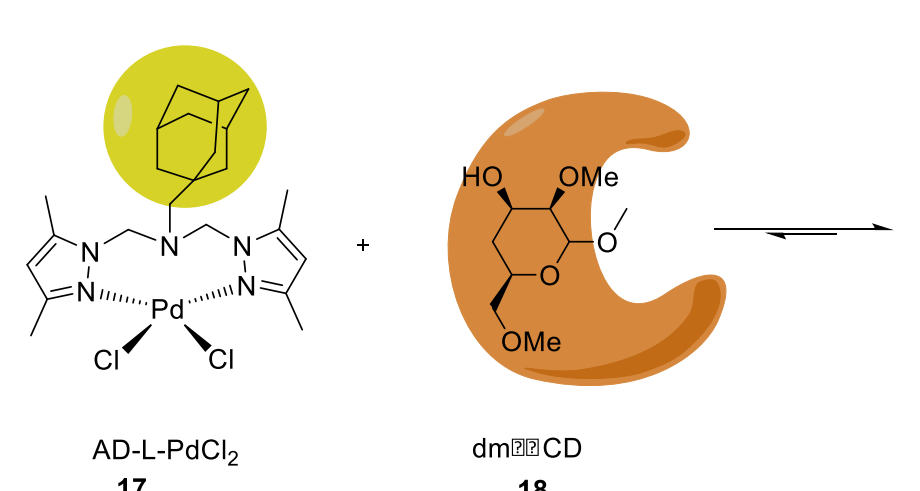

17

18

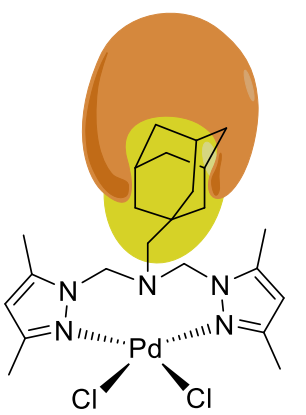

$\mathrm{AD}-\mathrm{L}-\mathrm{PdCl} \mathrm{d}_{2} \subset \mathrm{dm}$ ? ? $\mathrm{CD}$

19

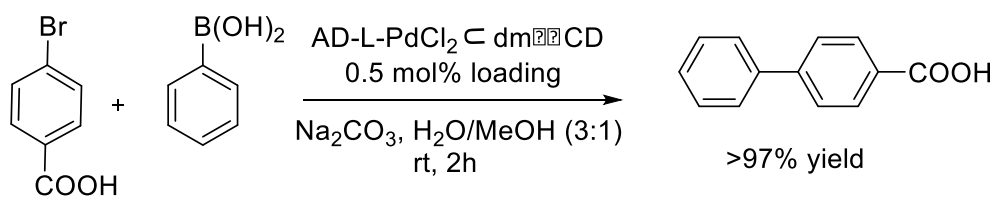

Scheme 15 Supramolecular catalyst for aqueous SMC developed by Hor and Young.[32]

Lang and $\mathrm{Li}$ reported a $\mathrm{PdCl}_{2} /$ sulfonate-tagged phenanthroline precatalyst $\mathbf{2 0}$ for the SMC at $100^{\circ} \mathrm{C}$ in water (Scheme 16).[33] The cross-coupling products were obtained in good to excellent yields (TON upto 1980). 


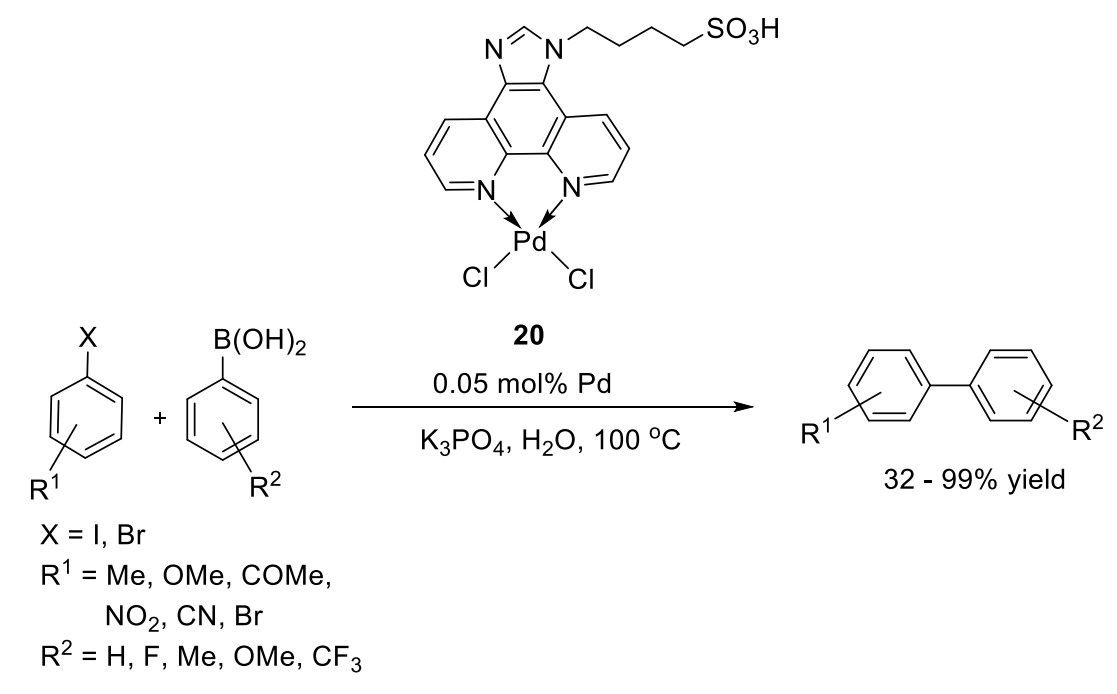

Scheme 16 Sulfonate-tagged phenanthroline palladium precatalyst for SMC in water.[33]

\section{ii) Imidates:}

Water-soluble palladium $(\mathrm{II})$ complexes trans-[$\left[\mathrm{Pd}(\text { imidate })_{2}(\mathrm{PTA})_{2}\right]$ (imidate $=$ succinimidate (suc) 21, maleimidate (mal) 22, phthalimidate (phthal) 23 or saccharinate (sacc) 24) have shown to efficiently catalyze SMC of synthetically challenging substrates. The antiviral nucleoside analogue 5-iodo-2'-deoxyuridine 25 was used as substrate for the formation of the corresponding biaryl $\mathbf{2 6}$ in water under mild conditions (TON $=96)$.[34] Upon increasing the reaction time (48 hours), lower catalyst loadings $(0.1 \mathrm{~mol} \%)$ could also be used, without any appreciable erosion of the yield (Scheme 17). 


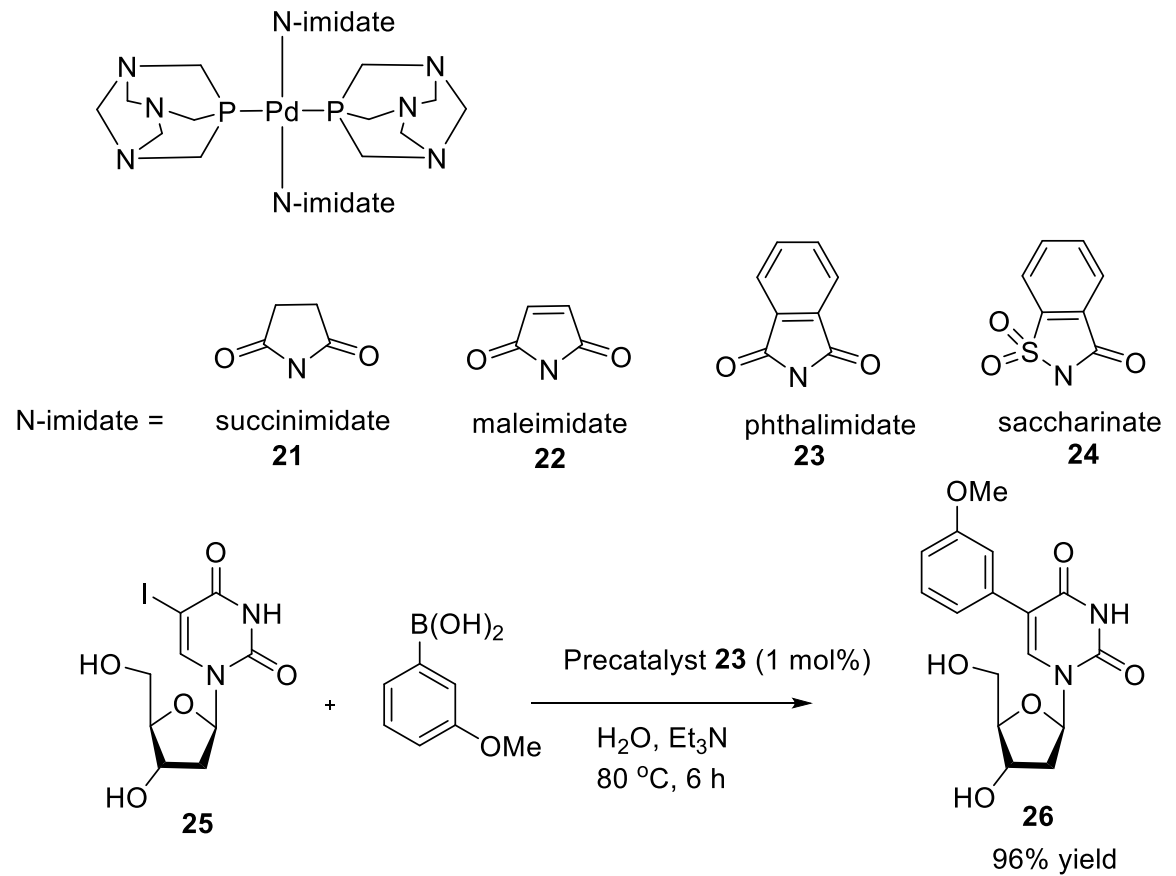

Scheme 17 Imidate as ligands for the SMC of 5-iodo-2'-deoxycytidine developed by Serrano and co-workers.[34]

\section{iii) Pyrimidines:}

Prof. B. Davis reported an active pyrimidine ligand 27a in 2009 for the aqueous SMC.[35] Inspired by this work, Chalker and coworkers[36] developed a melaminepalladium catalyst $\mathbf{2 7 b}$ for the SMC in water (Scheme 18). The advantages of the melamine ligand over pyrimidine ligands are as follows:

i) It is less expensive than the pyrimidine.

ii) It is soluble in both water and organic solvents. 
iii) The melamine-palladium catalyst can be cross-linked by reaction with formaldehyde to generate an insoluble polymeric catalyst $\mathbf{2 8}$ that can be recovered after the cross-coupling.

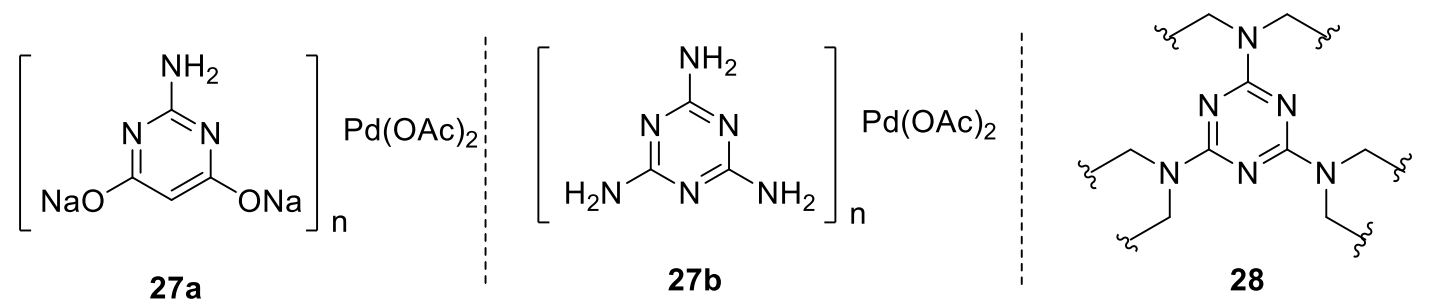

Homogeneous catalysis

Recoverable catalyst<smiles>CC(C)(C)c1ccc(-c2ccc(C(=O)O)cc2)cc1</smiles>

Scheme 18 Davis' ligand 27a for aqueous SMC. Crosslinked and related insoluble melamine-palladium catalysts for the SMC in water developed by

Chalker and coworkers.[36]

\section{iv) Amines:}

Zhou and coworkers[37] investigated the influence of the chelate ring size (i.e. 5 or 6), and the relative position of both $N$-donors and bulkiness of $N$-aryl substituents in amine-bridged bis(phenol) ligands $(\mathbf{2 9}, \mathbf{3 0}$ and $\mathbf{3 1})$ on the palladium-catalyzed SMC (Scheme 19). The homocoupling of arylboronic acid could be completed in neat water with the aid of a catalytic amount of $p$-toluenesulfonyl chloride $(\mathrm{TsCl})$ in a very short time under anaerobic or aerobic conditions. Interestingly, the same catalytic system 
was efficient for the SMC in aqueous acetone under aerobic conditions in the absence of $\mathrm{TsCl}$.

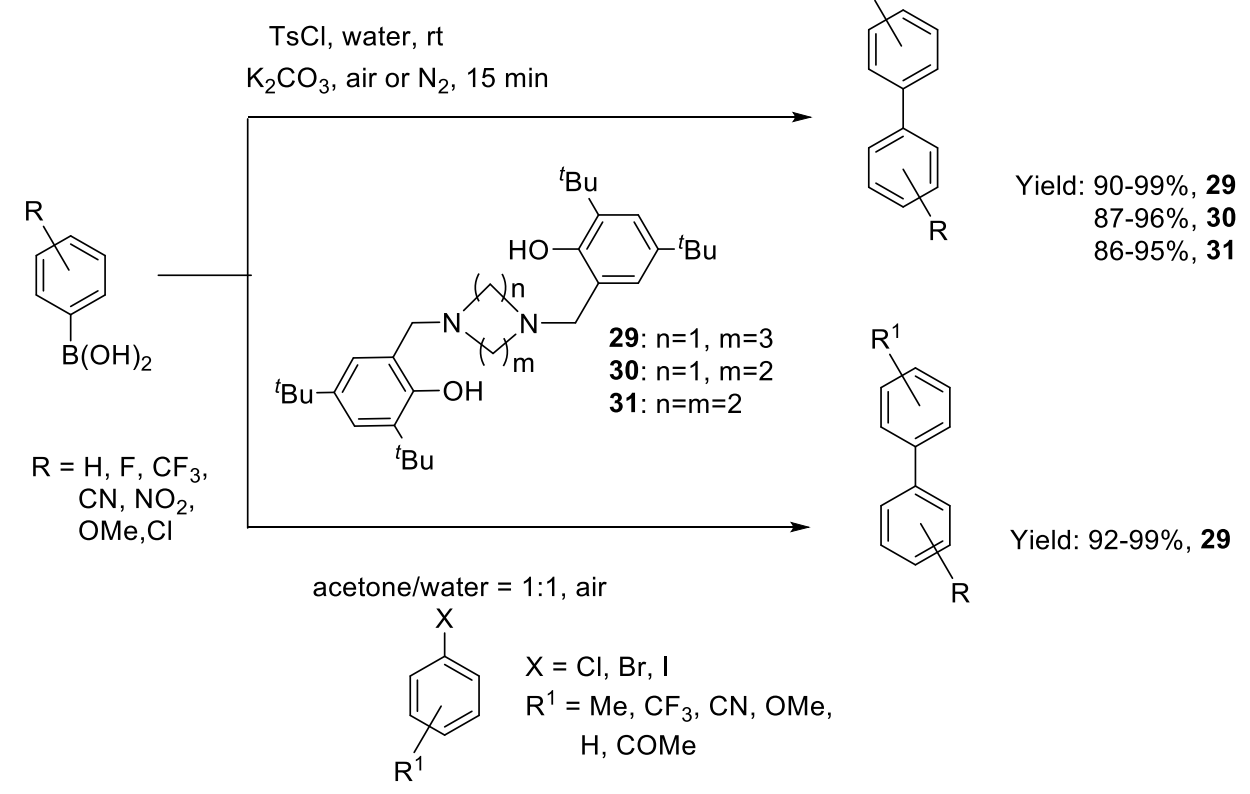

Scheme 19 Amine-bridged bis(phenol) ligands for the aqueous C-C cross-coupling reactions.[37]

\section{v) Orthometallated palladacycles:}

Palladacycles are interesting because they are believed to release highly active $\operatorname{Pd}(0)$ species at a very slow rate, which prevents the deactivation of $\operatorname{Pd}(0)$ such as nanoparticle formation, thus achieving high turnover numbers. Palladacycles are 

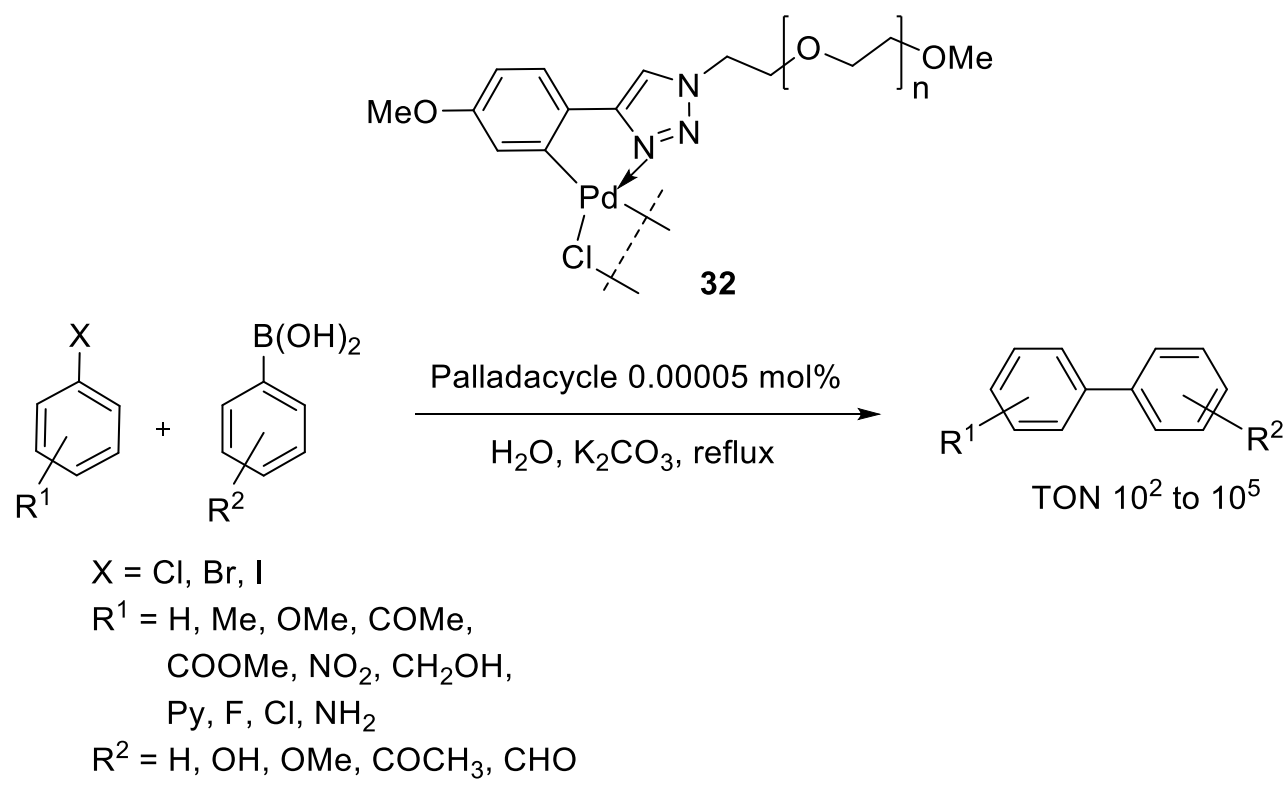

Scheme 20 SMC in water with an orthometallated aryltriazole palladium complex bearing a PEG solubilizing unit.[38]

formed by $\mathrm{C}-\mathrm{H}$ activation of aromatic moiety near a coordination site in the ligand. A novel water-soluble palladacycle 32 has been reported by Ding (Scheme 20).[38] The catalyst exhibited superior catalytic activity towards the SMC in neat water with TONs of up to $9.8 \times 10^{5}$. In addition, the catalyst could be reused at least 3 times without significant loss of activity.

Bora and coworkers studied $O$-Aryloxime ether analog $\mathbf{3 3}$ as ligands in the palladiumcatalyzed SMC of aryl bromides and aryl boronic acids in water at room temperature.[39] The reaction conditions for the cross-coupling were optimized using $\mathrm{PdCl}_{2}$ and $\mathrm{Pd}(\mathrm{OAc})_{2}$ under aerobic conditions (Scheme 21). To the best of our knowledge, this is the only example of an oxime ether used as a ligand. The aryl ring of the aryloxime ether is believed to undergo orthometalation through $\mathrm{C}-\mathrm{H}$ activation to form highly active palladacycle. 
<smiles>C/C(=N\Oc1ccc(Cl)cc1)c1ccccc1</smiles><smiles>CC(C)(C)[13C](=O)[O-]</smiles>

Scheme $21 O$-Aryloxime ether as ligand in palladium-catalyzed SMC in water.[39]
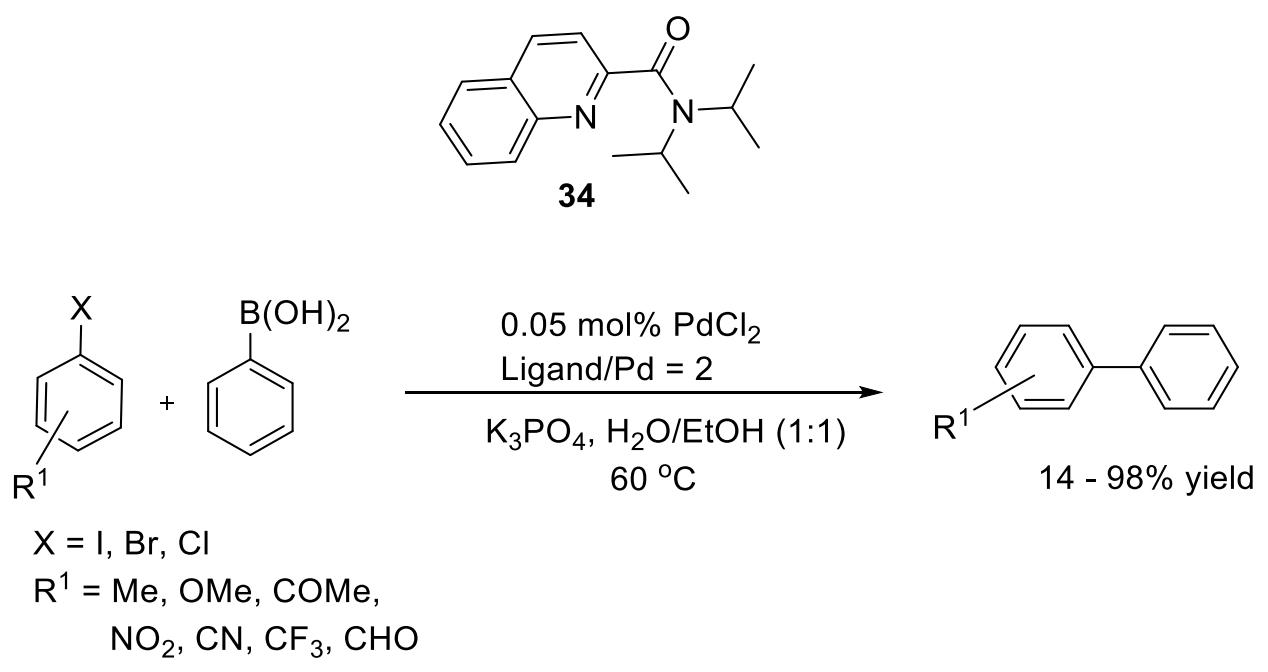

Scheme 22 Bidentate amide ligand based on a quinoline derivative used for the SMC in water.[40]

\section{vi) Amides:}

Jiang and Tan recently reported an SMC in water relying on the amide-bearing quinoline derivative 34 as a ligand.[40] With 0.05 mol\% Pd loading, they obtained up to $98 \%$ yield at $60-90^{\circ} \mathrm{C}$ under air (Scheme 22 ).

\section{vii) Hydrazones:}


Nallasamy and co-workers reported a palladium(II) complex $\mathbf{3 5}$ bearing a series of ONO tridentate heterocyclic hydrazone ligands for SMC of substituted aryl boronic acids with aryl chlorides in a water-toluene system $(9: 1)$.[41] The catalyst was highly active with 0.01 mol\% loading to afford $99 \%$ yield of the coupled product (Scheme 23).

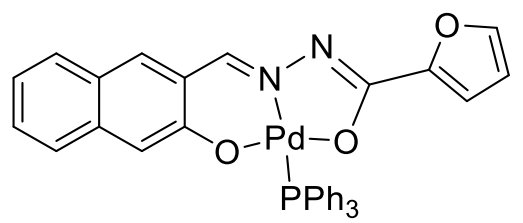

35

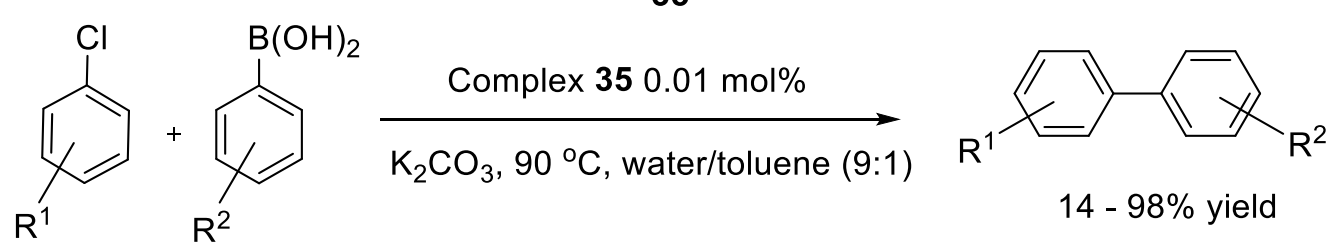

$$
\begin{aligned}
\mathrm{R}^{1}= & \mathrm{NO}_{2}, \mathrm{CN} \\
\mathrm{R}^{2}= & \mathrm{H}, \mathrm{Me},{ }^{t} \mathrm{Bu}, \mathrm{OMe}, \\
& \mathrm{OH}, \mathrm{Ph}, \mathrm{NMe}_{2}, \mathrm{Br}, \\
& \text { COMe }
\end{aligned}
$$

Scheme 23 Tridentate heterocyclic hydrazone ligand for SMC in water.[41]

\section{$2.3 \mathrm{~N}$-heterocyclic Carbene (NHC) Ligands}

NHC ligands are strong electron-donors and can be sterically demanding. Recently, their use in aqueous media has received attention. The carbene donor-carbon of an NHC is strongly basic ( $\mathrm{pK}_{\mathrm{a}}$ about 20$)$, which generally precludes their use as free ligands in aqueous media. thanks to the strong metal-NHC bond, metal complexes of water-soluble NHCs are often water soluble. The Haag group reported a highly active glycerol-dendron-supported $N$-heterocyclic carbene ligand $\mathbf{3 6}$ with $\mathrm{Pd}(\mathrm{OAc})_{2}$ as a catalyst (Scheme 24). A symmetrical ligand structure was designed to provide a 
larger micro-environment with the catalytic site at the core position. Deprotection of the dendritic-supported catalysts allowed to perform the catalytic reaction in neat water.[42]
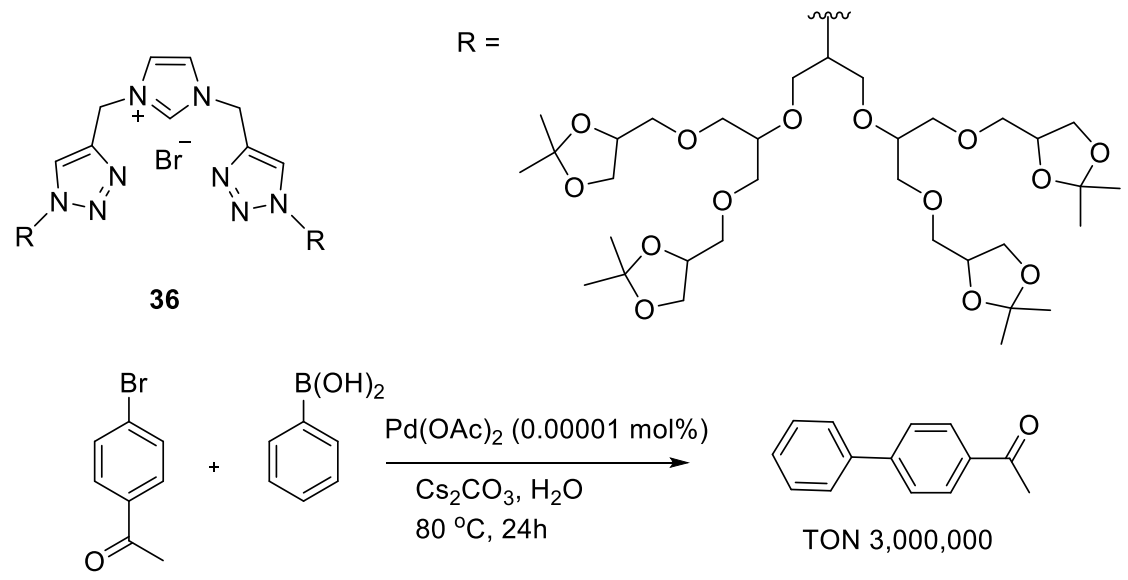

Scheme 24 Dendritic supported NHC-palladium catalysts for SMC with a L/Pd Ratio of 1.1:1.

Four water-soluble PEPPSI-type (pyridine, enhanced, precatalyst, preparation, stabilization and initiation) Pd-NHC complexes (37-40) were developed by Kühn and Pöthig for the SMC in water under air (Scheme 25).[43] Complex 37, bearing a 2,6diisopropylphenyl substituent, displayed the best catalytic activity for a variety of aryl bromides with a catalyst loading of $0.1 \mathrm{~mol} \%$ even at room temperature. The catalyst can be used in at in least four consecutive runs without significant loss of activity. 


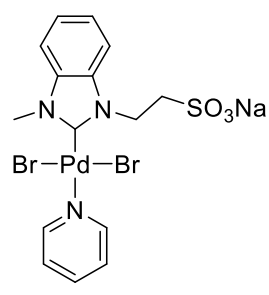

37

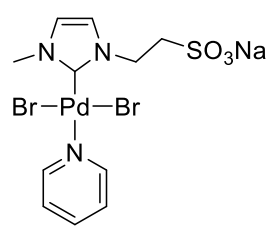

38

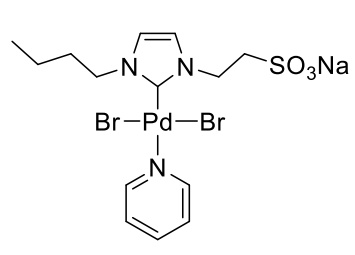

39

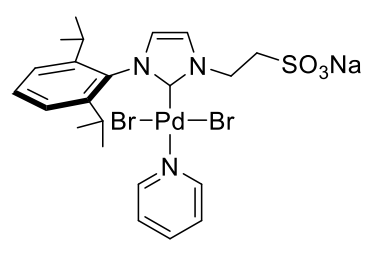

40

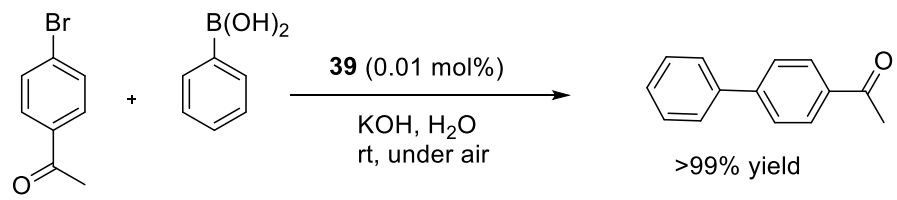

Scheme 25 Water-soluble PEPPSI-type -Pd-NHC complexes for aqueous SMC.[43] $($ PEPPSI $=$ pyridine, enhanced, precatalyst, preparation, stabilization and initiation $)$ An asymmetric SMC using chiral PEPPSI complex 41 incorporating bulky enantiopure $N$-heterocyclic carbenes was developed by Kündig and coworkers.[44] They obtained up to $85 \%$ yield and $80 \%$ ee for coupling of 1-halo-2methylnaphthalene with naphthylboronic acid. Unfortunately, the product was contaminated with an inseparable product resulting from homocoupling (Scheme 26).
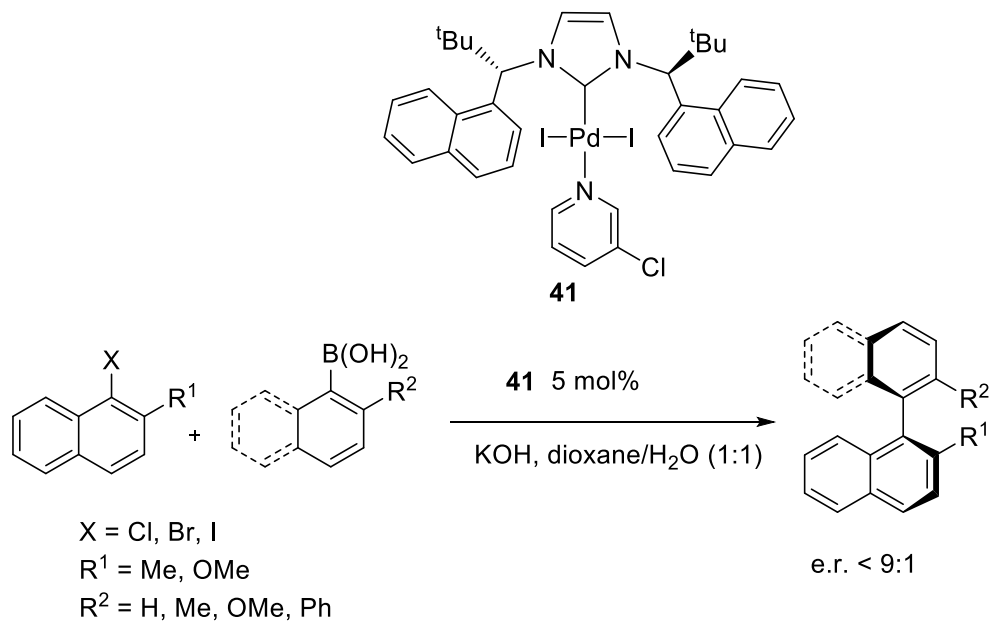

$\mathrm{R}^{1}=\mathrm{Me}, \mathrm{OM}$ e.r. $<9: 1$

Scheme 26 Asymmetric SMC with chiral PEPPSI complexes incorporating bulky $N$ heterocyclic carbene ligands.[44] 
Water-soluble $\mathrm{Pd}(\mathrm{II})(\mathrm{NHC})$ complexes $\mathbf{4 2}$ containing two sterically-hindered sulfonated groups have been prepared by Jesus.[45] These complexes are active catalysts for the SMC of aryl chlorides and boronic acids in mixtures of isopropyl alcohol/water or, in the case of water-soluble aryl chlorides, in pure water (Scheme 27). For some of the most hindered aryl chlorides, small amounts of monoarenes are formed via a competitive hydro-dehalogenation process.

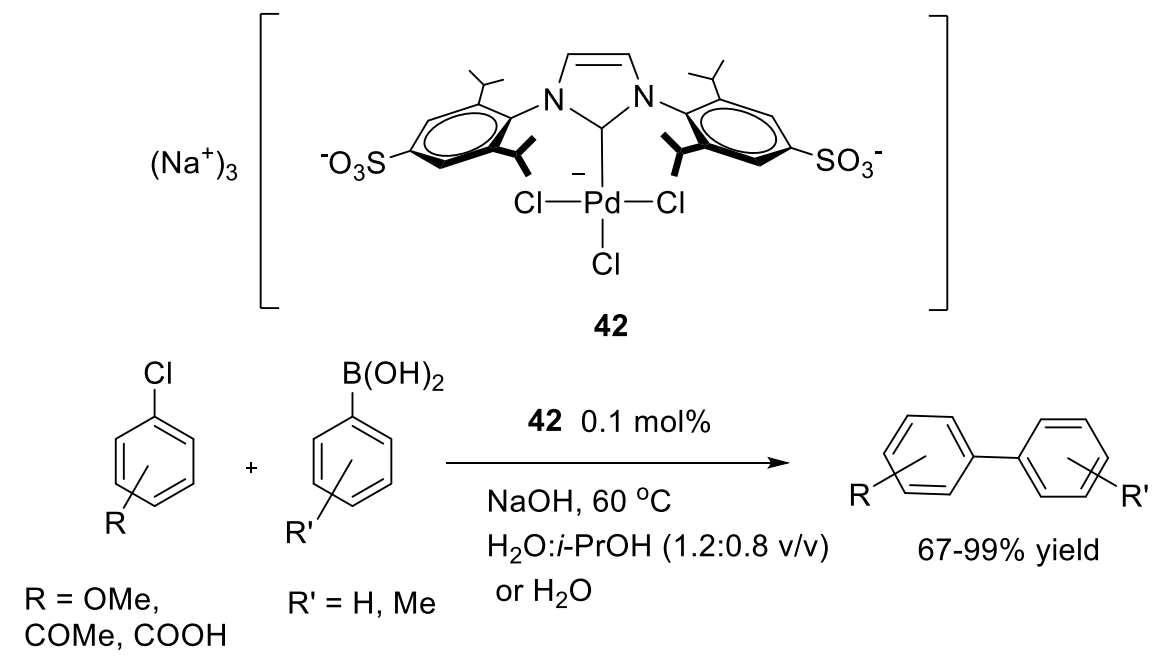

Scheme 27 Synthesis of biphenyls by SMC catalyzed by palladium(II) complexes bearing sulfonated N-Heterocyclic Carbenes.[45]

Palladium complexes with chelating, oligo-ethylene glycol-substituted bis-NHC ligands have been prepared by Strassner.[46] The resulting Pd-complex $\mathbf{4 3}$ displays excellent water solubility and very high catalytic activity. Up to 80 '000 TONs could be achieved in a $1: 1$ water methanol mixture at $100{ }^{\circ} \mathrm{C}$ (Scheme 28). The palladium complexes showed excellent solubility in water. Very high catalytic activity was achieved even at ppm catalyst loadings. 


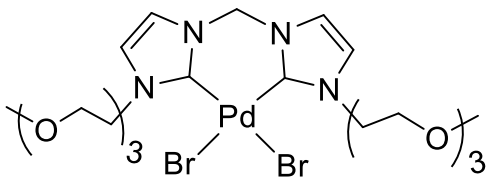

43

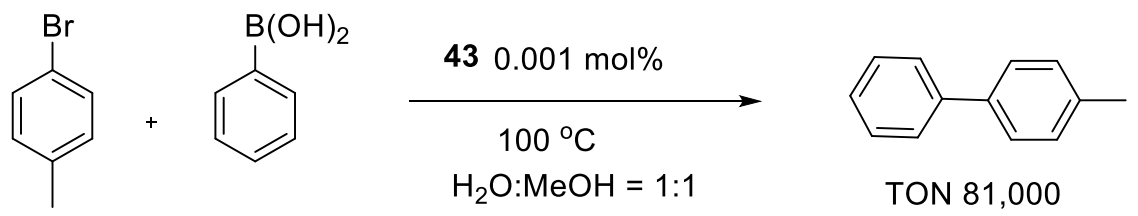

Scheme 28 Oligo ethylene glycol substituted bis-NHC ligands for SMC in a watermethanol mixture.[46]

A very similar complex $\mathbf{4 4}$ was also prepared by Wang and coworkers.[47] Deprotonation of carboxylic acid group rendered it water-soluble (Scheme 29).

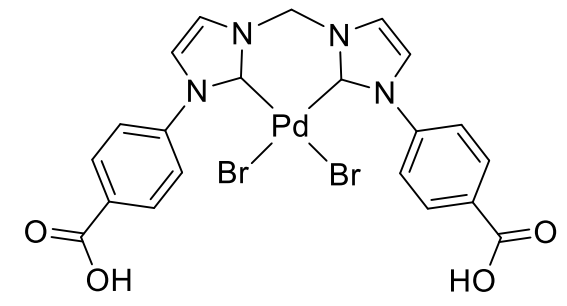

44

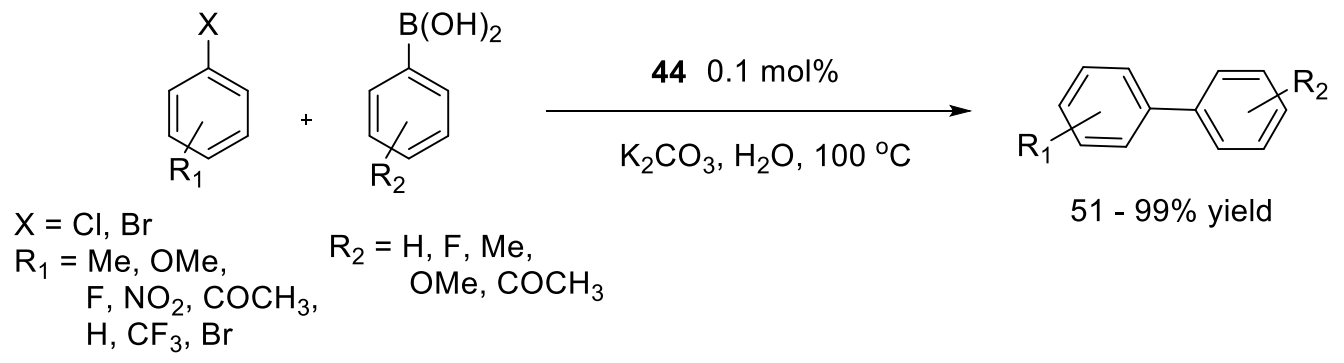

Scheme 29 Chelating-NHC-palladium complex for the SMC in water.[47]

In a study, Peris and Godoy compared four bis-NHC-palladium complexes $\mathbf{4 5}-\mathbf{4 8}$ for the SMC in water.[48] The bis-NHC-palladium complex $\mathbf{4 5}$, in which the two NHC ligands are in a relative cis configuration, afforded the best catalytic system, with 
TONs $>10^{5}$ for 4-bromoacetophenone and $3.7 \times 10^{4}$ for 4-chloroacetophenone (Scheme 30).

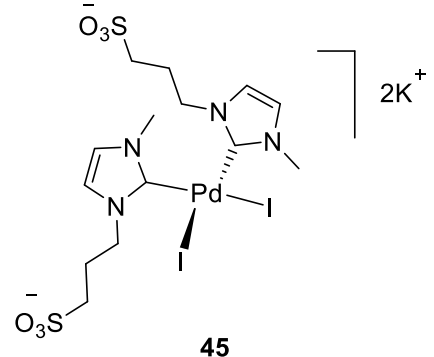

45

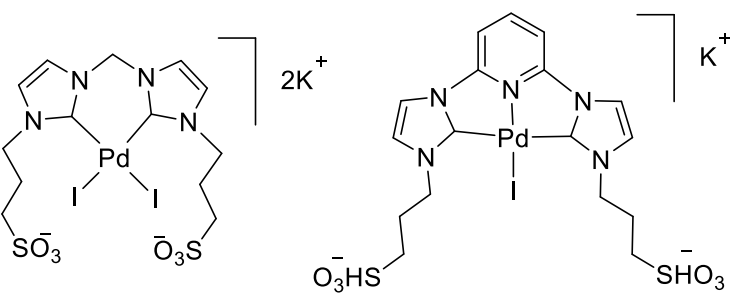

46
47<smiles></smiles>

48

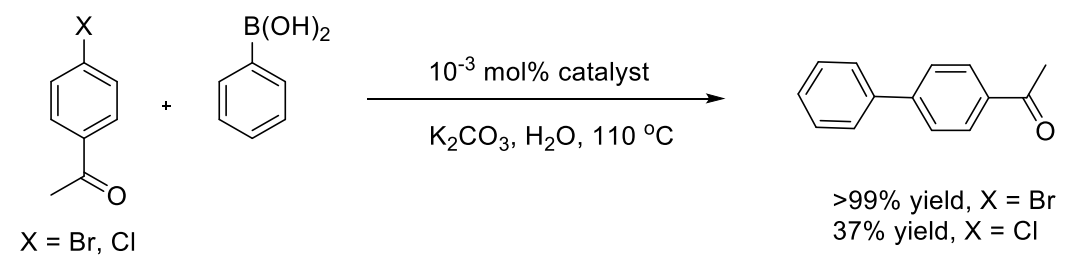

Scheme 30 Palladium catalysts with sulfonate-functionalized-NHC ligands for the

SMC in water.[48]

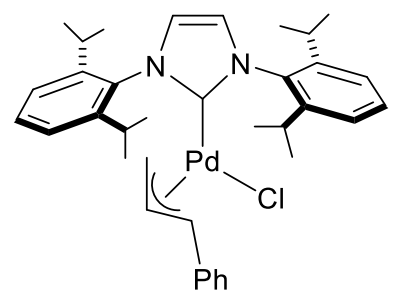

$$
[\mathrm{Pd}(\mathrm{IPr})(\operatorname{cin}) \mathrm{Cl}]
$$

49
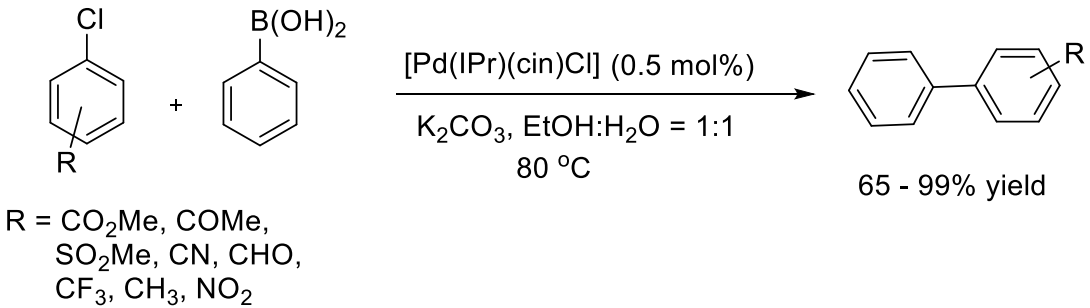

Scheme 31 An SMC in water based on a commercially available precatalyst.[49] 
Nolan and coworkers recently reported the SMC using a Pd-NHC catalyst at low catalyst loading.[49] The commercially available and air-stable [Pd(IPr)(cin)Cl] precatalyst 49 led to the formation of various functionalized biaryls from aryl chlorides and boronic acids under very mild conditions using a mixture of ethanol/water as solvent and an inorganic base (Scheme 31).

Liu and coworkers[50] reported the synthesis of water-soluble imidazolium salts $\mathbf{5 0}$ bearing poly(ethyleneglycol) moieties directly attached to an $\mathrm{N}$-atom of imidazole. The catalytic system generated in situ from a source of $\left[\mathrm{Pd}(\mathrm{OAc})_{2}\right]$, a precursor of imidazolium salt, and triethylamine catalyzes the SMC in water (Scheme 32).

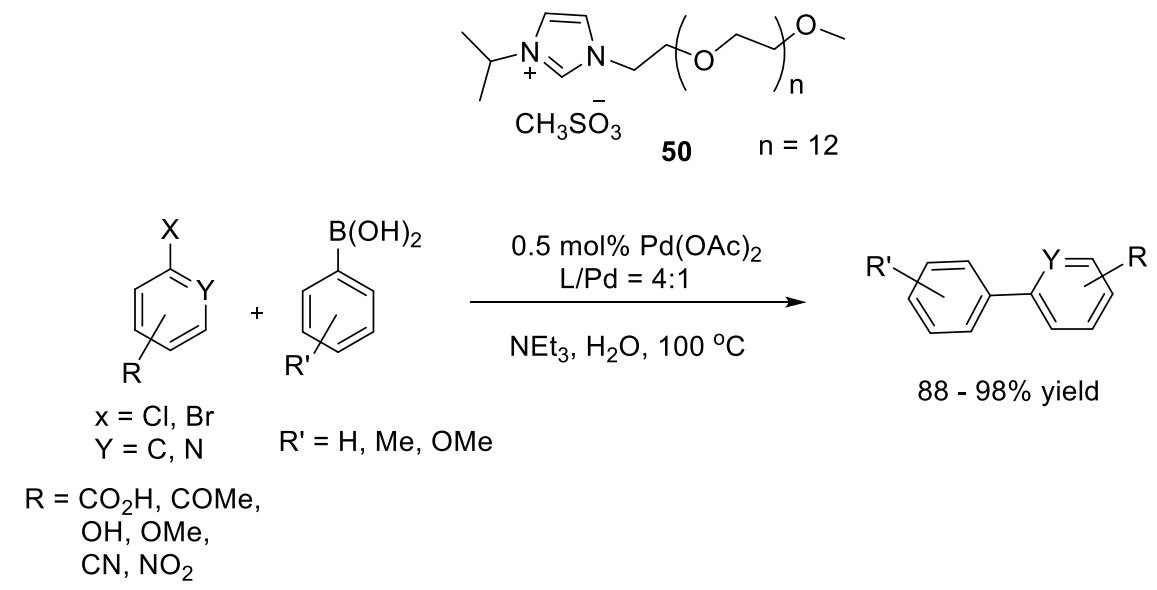

Scheme 32 Poly(ethylene glycol)-functionalized imidazolium salts-palladiumcatalyzed SMC in water.[50]

Karimi and coworkers showed that Pd-NHC polymers 51 can be used as catalyst for SMC in water (Scheme 33).[51, 52] Although the mechanism is not clear, this polymer showed very high activity for the coupling of aryl chlorides, together with excellent recyclability. 


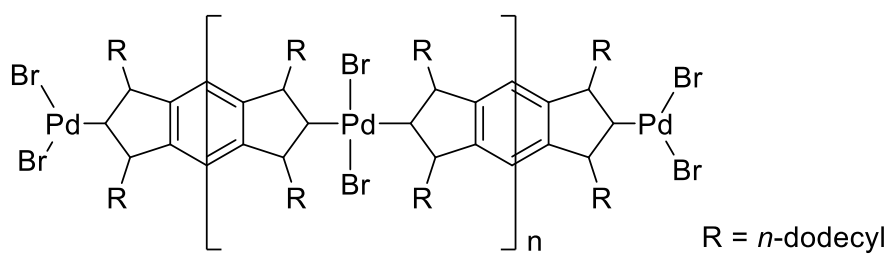

51

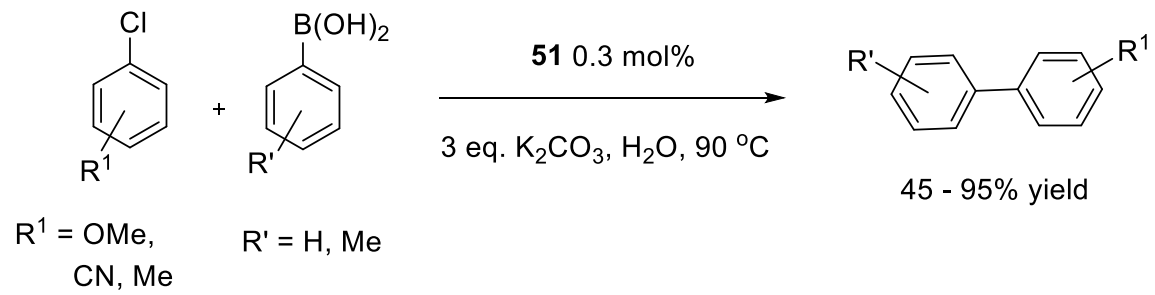

Scheme 33 Pd-NHC oligomers for aqueous SMC developed by Karimi.[51]

Recently, Nechaev and co-workers synthesized the six-membered ring NHC containing complex 52, which was used for the cross-coupling of heteroaryl bromides and chlorides with heterocyclic boronic acids in water (Scheme 34).[53] The crosscoupled products were obtained in very good yield with $0.5 \mathrm{~mol} \%$ catalyst loading (TON up to 200).

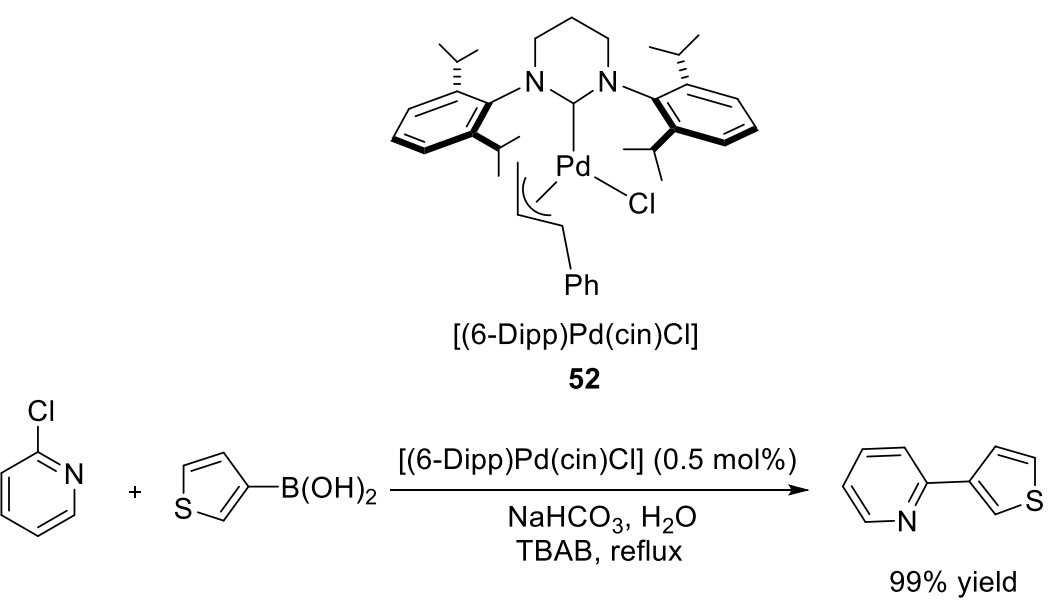

Scheme 34 Expanded ring NHC palladium complex 52 for the SMC in water.[53] 
The same year Cazin and co-workers reported on the synthesis of a mixed $\mathrm{PR}_{2} \mathrm{Ar}$ /NHC Pd complex 53 that was used in SMC of aryl chlorides using very low catalysts loadings in aqueous solutions (water/isopropanol 9:1) (Scheme 35).[54]
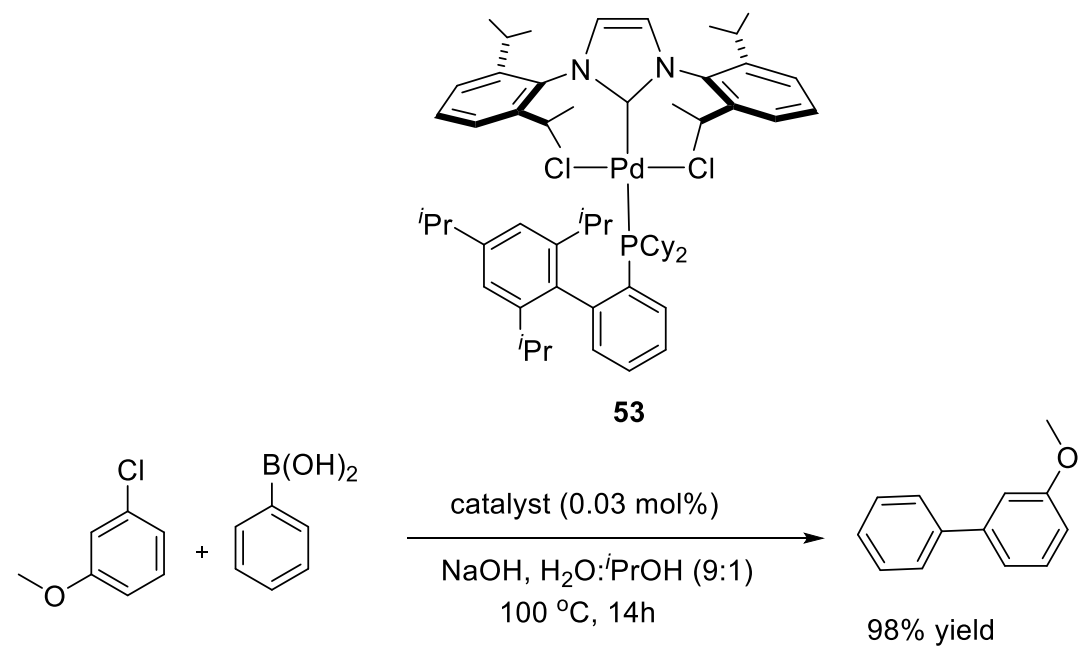

Scheme 35 Mixed phosphine/N-heterocyclic carbene palladium complexes for SMC in water.[54]
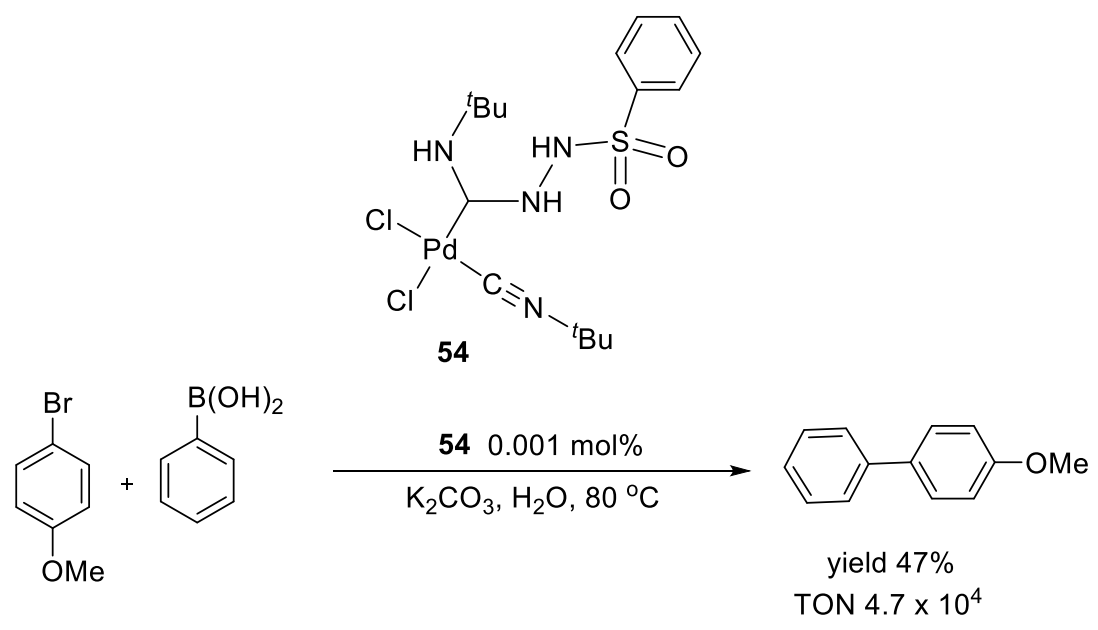

Scheme 36 Acyclic diaminocarbene (ADC) palladium complex 54 for SMC in water.[55] 
In an alternative strategy relying on acyclic carbene ligands, Boyarskiy and Luzyanin[55] reported palladium complexes with acyclic diaminocarbenes [Pd(ADCs)] (Scheme 36). The catalyst 54 efficiently catalyzed the SMC of organohalides with a range of aryl boronic acids at $80^{\circ} \mathrm{C}$ within $2 \mathrm{~h}\left(100^{\circ} \mathrm{C}\right.$ and $3 \mathrm{~h}$ for the chlorides). Biaryls were obtained in yields up to $99 \%$ and with maximum TONs of $9.9 \times 10^{3}$ (for aryl iodides), $4.7 \times 10^{4}$ (for aryl bromides), and $9.2 \times 10^{3}$ (for aryl chlorides).

\subsection{Homogeneous SMC for Chemical Biology Applications}

More recently, the SMC has found applications in the context of chemical biology. Indeed, both reactants (i.e. arylhalides and boronic acids) and products (i.e. biaryls) can be regarded as bio-orthogonal.[35, 56-61] In this context however, high catalyst loadings are routinely required for reactions performed in a biological environment.[35, 56, 57, 60, 62-70] Ueno and coworkers anchored a palladium moiety within a ferritin container to yield an artificial metalloenzyme. The resulting artificial metalloenzyme however did not outperform the free cofactor (no enantioselectivity, turnover frequency: $\left.3500 \mathrm{~h}^{-1}\right)$.[57]

The Davis group reported a convenient catalyst for the SMC using a modified protein as substrate.[35, 59, 71, 72] An effective ADHP (2-amino-4,6-dihydroxypyrimidine)based catalyst system $\left[\mathrm{Pd}(\mathrm{OAc})_{2}(\mathrm{ADHP})_{2}\right] \mathbf{5 5}$ was gave full conversion $(>95 \%$ yield, 95 TON) between a protein bearing aryl iodide moiety and a broad range of aryl/vinyl-boronic acids.[63] Recently, in a continuous effort to apply transition-metalmediated reactions in living systems, the Davis' group demonstrated the first application of the SMC on the outer-membrane protein $\mathrm{OmpC}$ of Escherichia coli 
cells.[60] Here, a bacterial surface protein, OmpC was engineered by incorporation of 4-iodo-phenylalanine (Scheme 37). A reaction in the presence of a fluorescent boronic acid as coupling partner, catalyzed by $\left[\mathrm{Pd}(\mathrm{OAc})_{2}(\mathrm{ADHP})_{2}\right](200 \mathrm{~mol} \%)$, afforded the fluorescent cross-coupled product, anchored on the bacterial surface. The ADHPbased catalysts showed excellent labelling efficiency and low cytotoxicity in bacteria cells, although the reaction was not catalytic..[73]
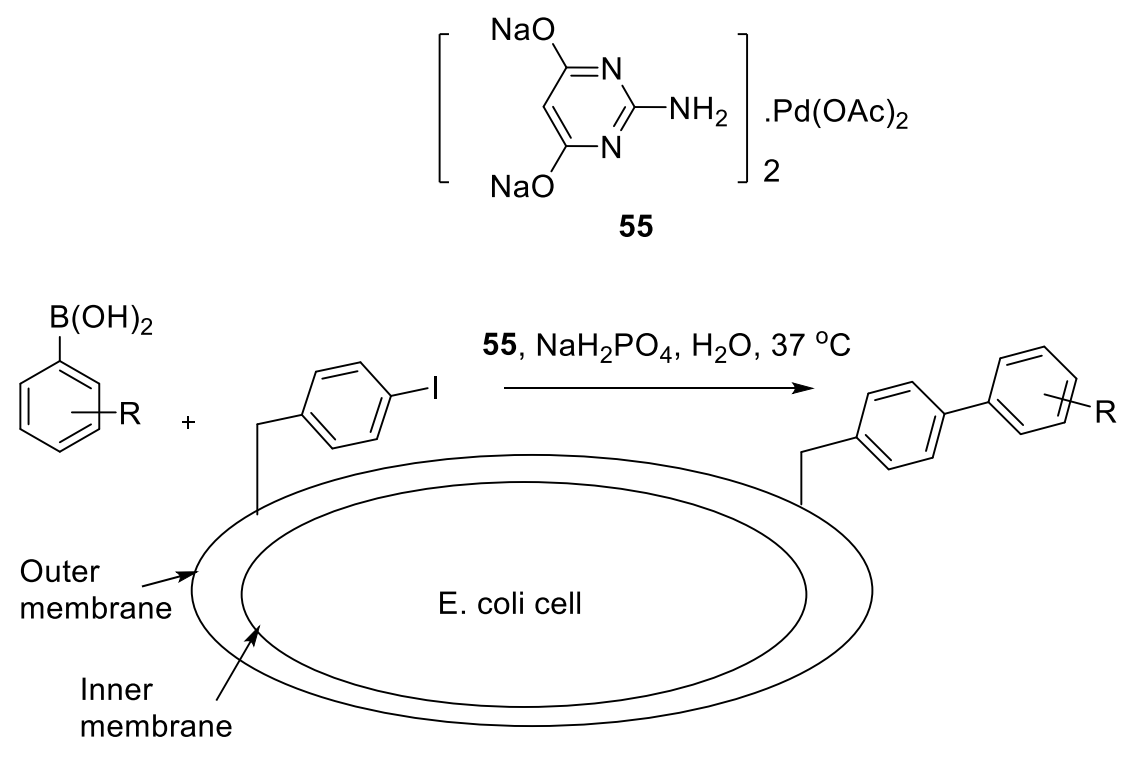

Scheme 37 (2-amino-4,6-dihydroxypyrimidine)-based catalyst system for SMC on the outer-membrane protein OmpC of E. coli developed by Davis group.[60]

Wang and Chen reported on a water-soluble $N$-heterocyclic carbene (NHC)-stabilizedpalladium complex for the SMC of biomolecules under mild conditions in water (Scheme 38).[67] The Pd-NHC complex 56 bearing hydrophilic groups was an efficient catalyst for the SMC of various unnatural arylhalide-bearing amino acids (TON up to 95). The authors further exploited this catalytic system for the rapid 
bioorthogonal labeling of proteins on the surface of mammalian cells. In this case, they used a stoichiometric amount of catalyst but there is no mention of yield or TON.

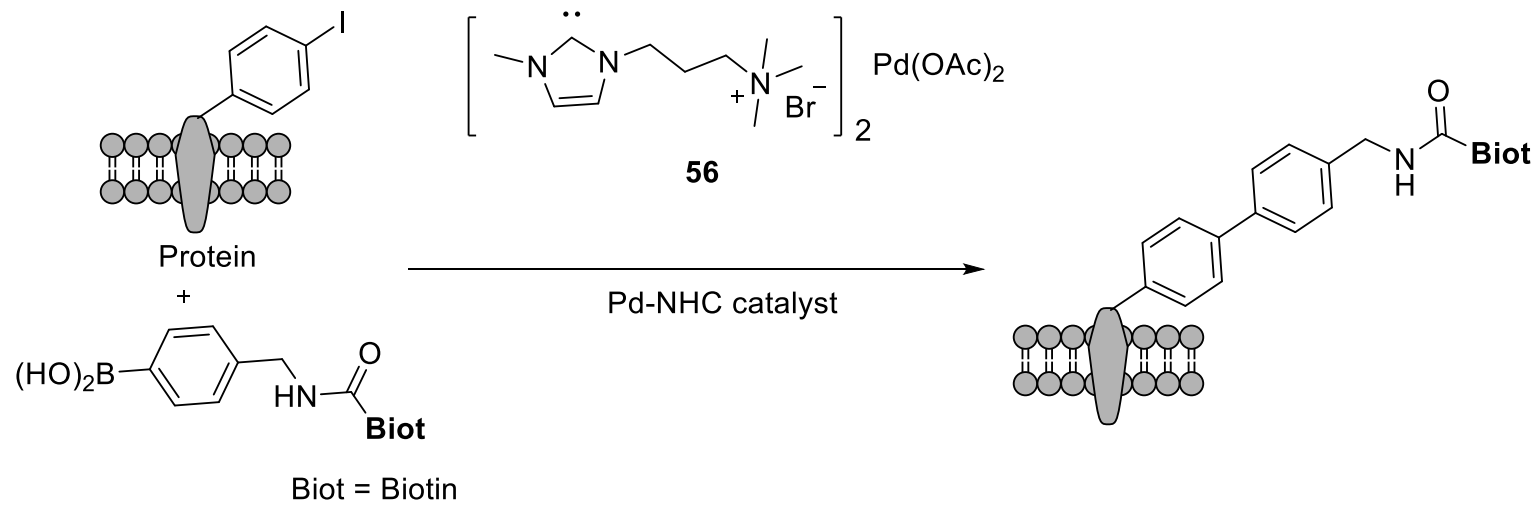

Scheme 38 Pd-NHC catalyzed SMC on a cellular system developed by Wang and Chen.[67]

\section{Heterogeneous SMC in water}

In view of the high cost and the shortage of palladium, its recovery and recycling is an important issue for any large scale application. Therefore, a variety of inorganic and organic solid-supported catalytic systems have been developed to address these challenges. In this context, heterogeneous Pd-catalysts are more attractive than the homogeneous Pd-catalysts as their recovery is facilitated. Residual palladium is a particular concern in the synthesis of pharmacophores, where very stringent precious metal restrictions apply. Unfortunately, compared to their homogeneous counterparts, solid-supported catalysts often suffer from lower activity and selectivity. It is thus highly desirable to develop highly efficient supported SMC catalysts. 


\subsection{Supported catalysts}

Polymer-modified nanoparticle-supported catalysts have generated a lot of interest due to their unique properties. Polymer supports can be chemically modified easily with functional groups to coordinate with transition metals, potentially improving the longterm stability of the catalyst. Moreover, the nanoparticles may enhance the catalytic performance thanks to their large surface-to-volume ratios and high densities of active sites relative to the bulk metals. Polymer-modified nanoparticles are expected to combine the advantages of both the homogeneous and heterogeneous catalysts.

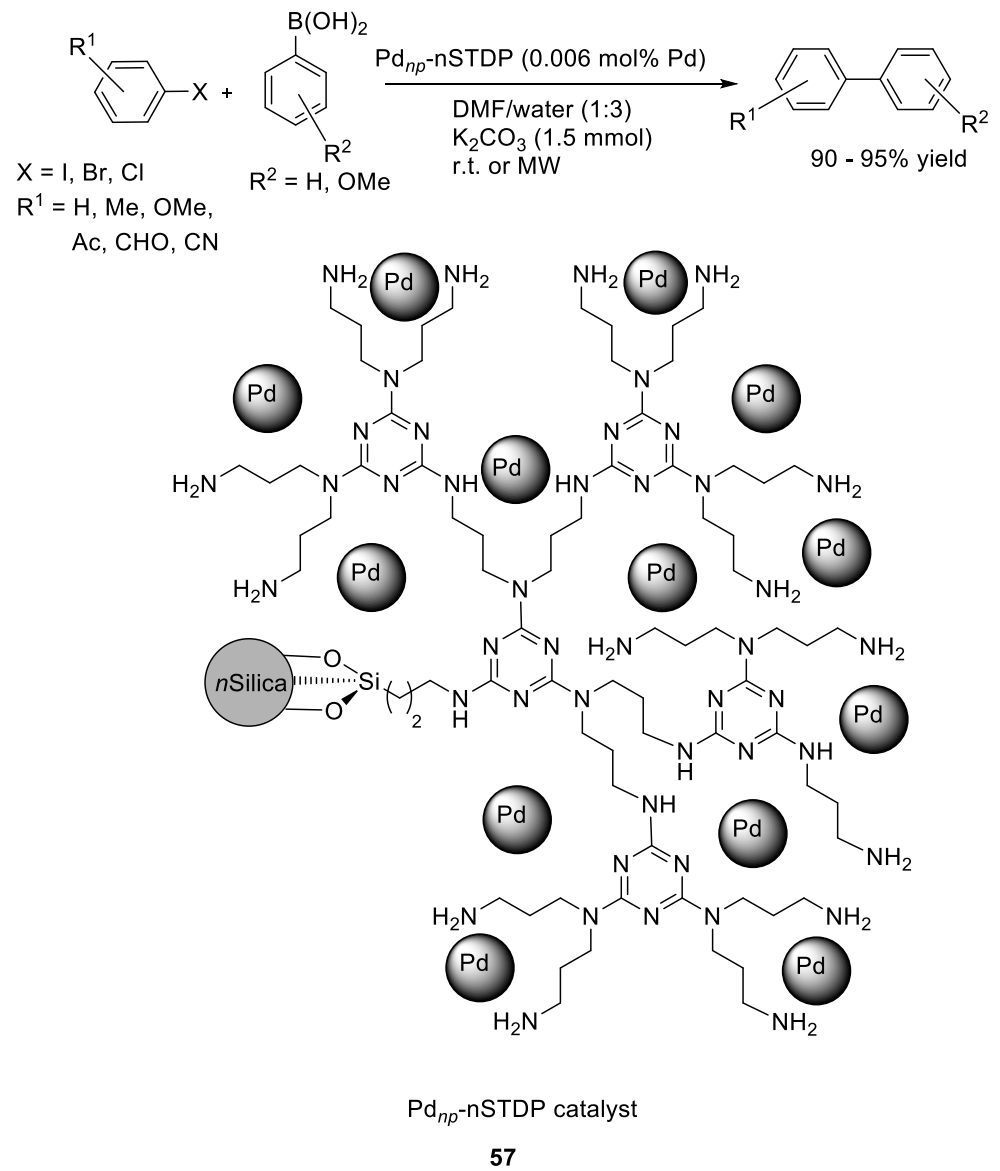

Scheme 39 Palladium nanoparticles on a nano-silica triazine dendritic polymer as catalyst for aqueous SMC.[74] 
Isfahani and colleagues[74] recently prepared a catalyst 57 by immobilizing palladium nanoparticles on a nano-silica triazine dendritic polymer. This catalyst exhibited high activity for the SMC even with $0.006 \mathrm{~mol} \%$ palladium loading (Scheme 39). In addition, it could be reused six times with no apparent decrease in yield. The catalyst was recovered by centrifugation, which might be a limitation for large scale applications.

To circumvent the challenge associated with separation of catalyst from the reaction medium by filtration or centrifugation, magnetically-separable catalysts have attracted much attention recently. A magnetically responsive polymer nanocomposite $\mathrm{Fe}_{3} \mathrm{O}_{4} @$ poly(undecylenic acid-co-4-vinyl pyridine-co-sodium acrylate) (PUVS) 58 was introduced by Bian.[75] This catalyst exhibited excellent catalytic activity for
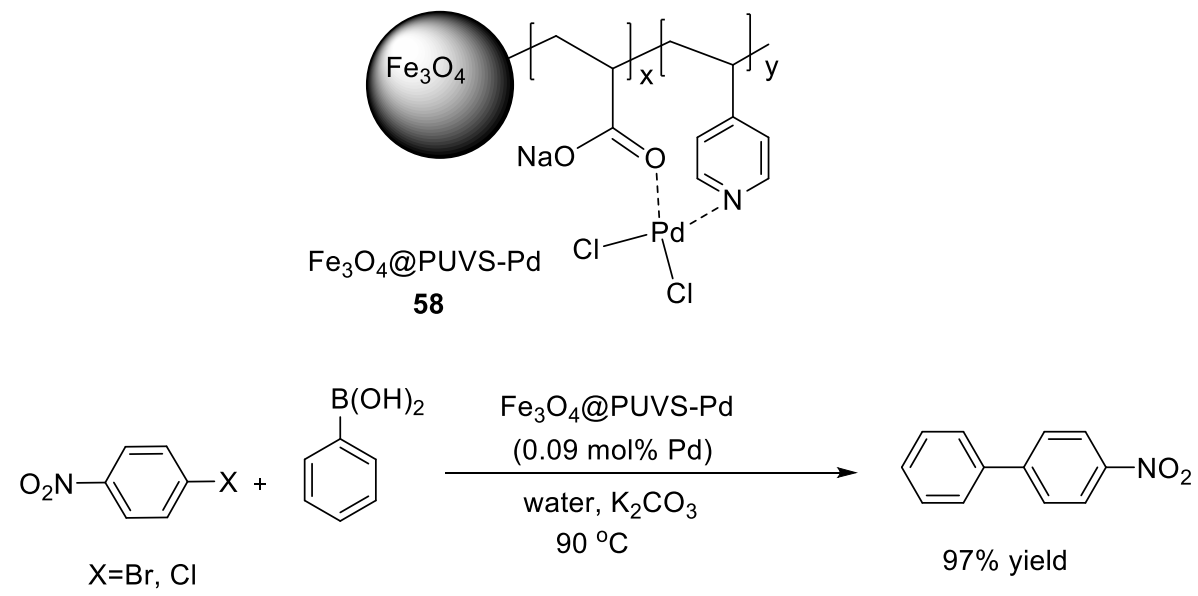

Scheme 40 Magnetic polymer-nanocomposites as catalyst for SMC in water developed by Bian.[75] PUVS = poly(undecylenic acid-co-4-vinyl pyridine-co-sodium acrylate) 
both Heck and SMC in water, and could be conveniently separated and recovered by applying a permanent magnet (Scheme 40). The supported catalyst could be used consecutively for six runs without significant loss of catalytic activity.

A novel magnetic nanoparticle-supported oxime palladacycle catalyst $\mathbf{5 9}$ was prepared and characterized by Gholinejad.[76] The magnetically recoverable catalyst was employed at room temperature for the SMC of aryl iodides and bromides in aqueous media. The catalyst was shown to be highly active under low Pd loading (0.3 mol\%) (Scheme 41). The catalyst could be easily recovered from the reaction mixture using an external magnet and reused for six consecutive runs without significant loss of
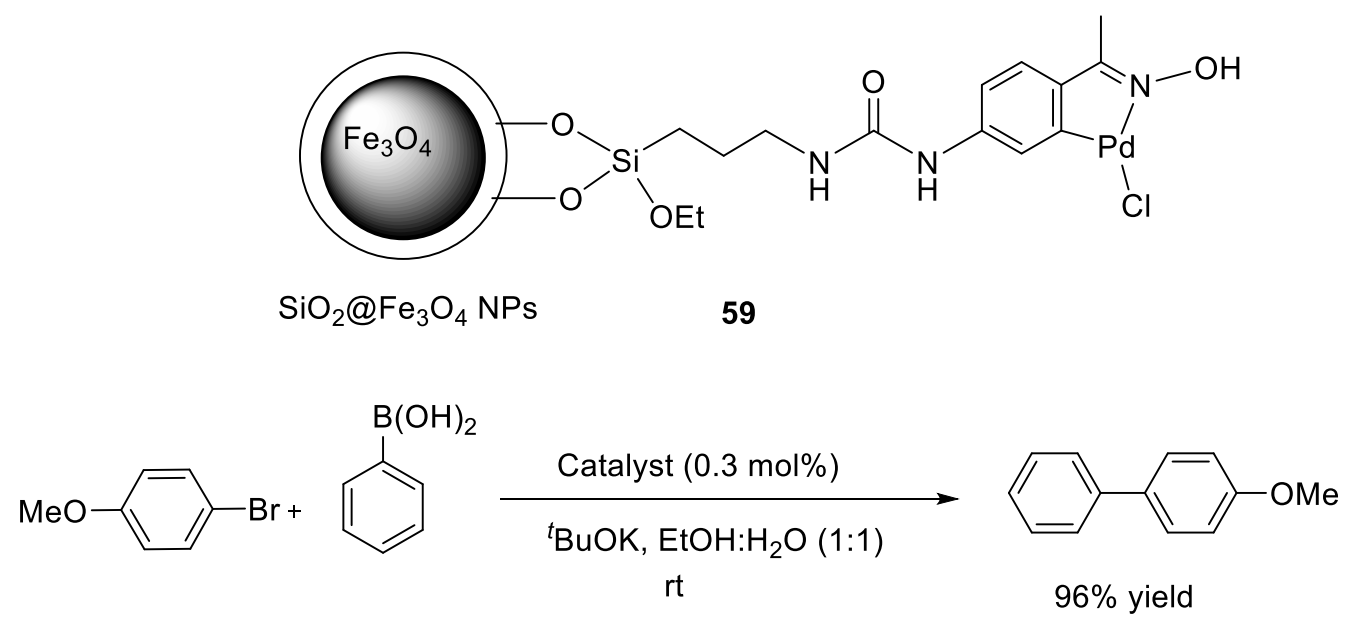

Scheme 41 Magnetic nanoparticle-supported oxime palladacycle catalyst for the SMC in water.[76]

activity. A similar kind magnetically-separable palladium catalyst was also developed by Karimi and co-workers relying on imidazolium ionic liquid bearing triethylene glycol moieties on the surface of silica-coated iron oxide nanoparticles.[77] The biaryl 
products were obtained upto $95 \%$ yield with $0.25-0.50 \mathrm{~mol} \%$ Pd loading under argon atmosphere.

$\mathrm{Li}$ and co-workers recently reported on a recyclable ordered mesoporous magnetic organometallic catalyst $\mathbf{6 0}$ for SMC in water (Scheme 42).[78] They immobilized the catalyst precursor onto undoped and functionalized ordered mesoporous silicas (MCM-41) coated on $\mathrm{Fe}_{3} \mathrm{O}_{4}$ magnetic microspheres. The catalytic efficiencies were comparable with those of the homogeneous catalysts, and they could be easily recycled (eight times) for reuse by applying an external magnet.

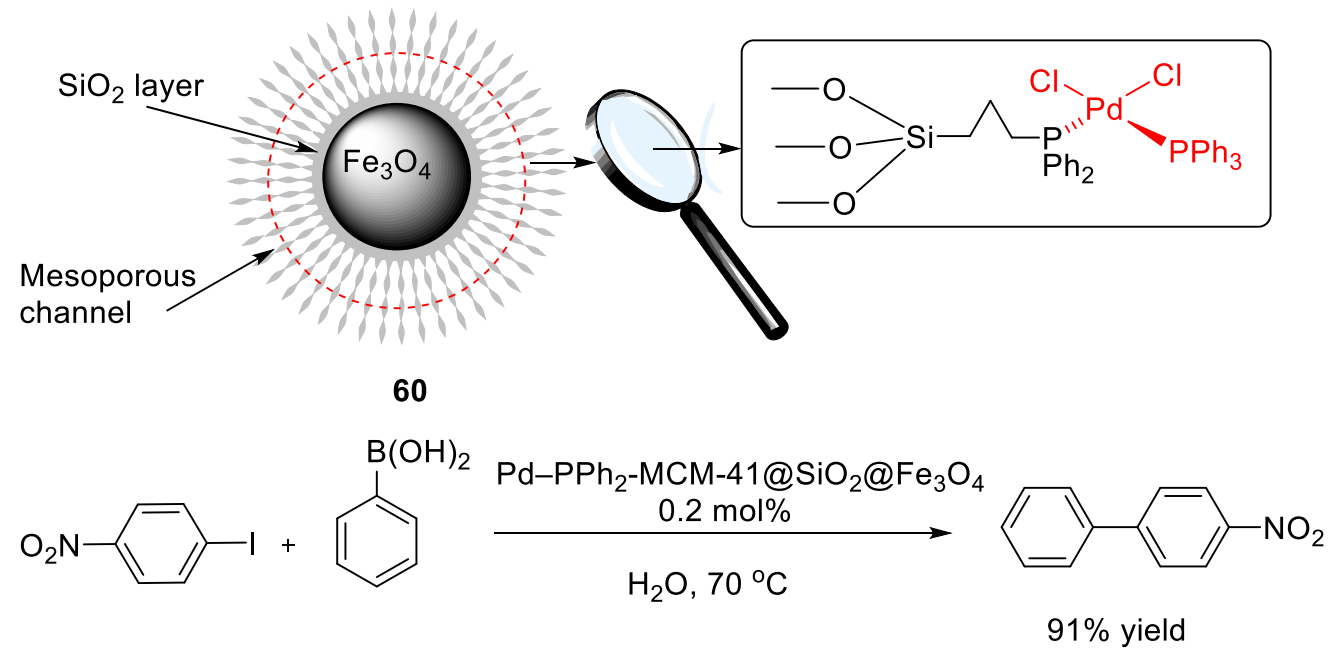

Scheme 42 Palladium complexes anchored to an MCM-41 thin layer coated on $\mathrm{Fe}_{3} \mathrm{O}_{4}$ microspheres as catalyst for the SMC in water.[78]

Trzeciak and co-workers reported palladium supported on triazolyl-functionalized polysiloxane 61, 62 as a recyclable catalyst for the SMC of aryl bromides with phenylboronic acid at $60{ }^{\circ} \mathrm{C}$ in a 2-propanol-water mixture (Figure 1).[79] In recycling experiments, very good results were obtained in eight consecutive runs. 


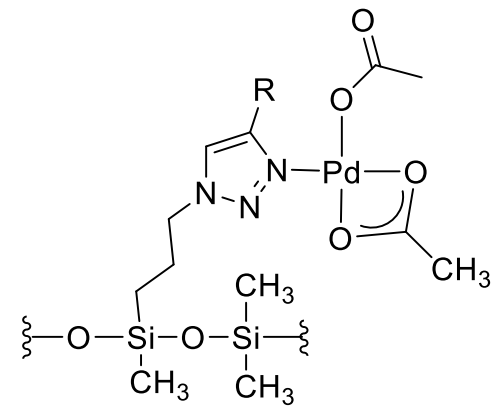

61

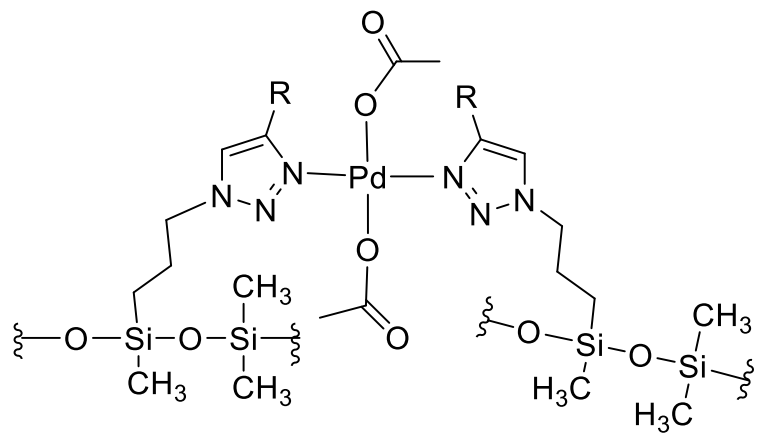

62

Figure 1 Triazole-functionalized siloxane co-polymers as suppors for palladiumcatalyzed SMC.[79]

To overcome less accessible active sites for immobilized or supported palladium catalysts, Ma and co-workers recently developed a self-supported hollow material with tunable cavities. This material is potentially interesting thanks to its inherent features including: i) high surface area, ii) low density iii) easy recovery, iv) low cost, and v) surface permeability. Relying on tetrabutylphosphonium bromide $\left(\mathrm{Bu}_{4} \mathrm{PBr}\right)$ as template, Ma prepared a mesoporous $\mathrm{Pd}-\mathrm{Fe}$ alloy magnetic spheres catalyst with a hollow chamber.[81] This catalyst displays high activity in the SMC. In a subsequent study, Ma reported a high-performance palladium catalyst $\mathbf{6 3}$ resulting from the covalent anchoring of a Schiff-base ligand, $N, N^{\prime}$-bis(3-salicylidenaminopropyl)amine (salpr), on the surface of hollow magnetic mesoporous spheres (HMMS) followed by immobilization of $\mathrm{Pd}(0)$ (Scheme 43).[80] The heterogeneous catalyst could readily be recovered from the reaction mixture and recycled six times without any loss of activity. 

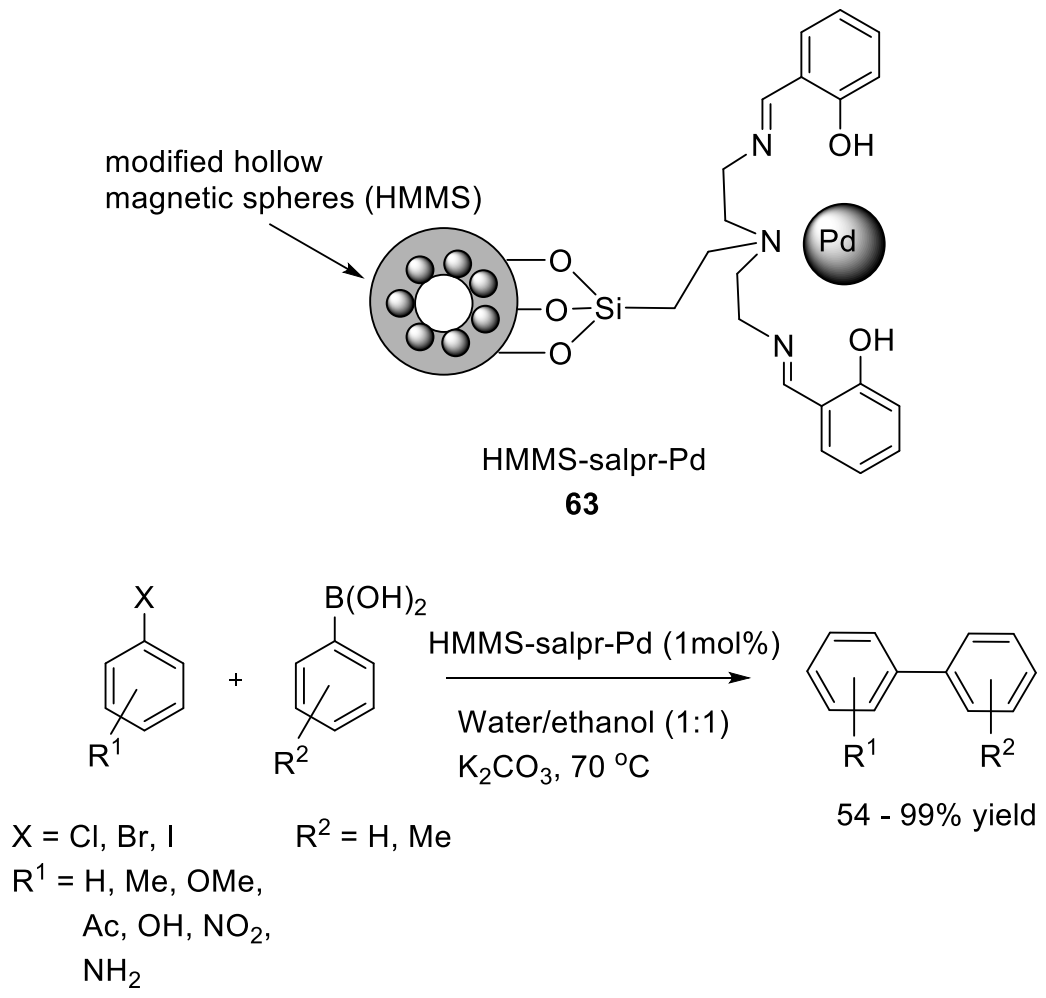

Scheme 43 Pd nanoparticles immobilized on modified hollow magnetic spheres

(HMMS) for SMC in water developed by Ma.[80]

Recently, Siril and co-workers reported a palladium-polyaniline (Pd-PANI) nanocomposite for the SMC in aqueous media (Scheme 44).[82] PANI is a conducting polymer which was used as a catalyst support. With this system, they showed that the SMC proceeds much faster in water than in toluene.

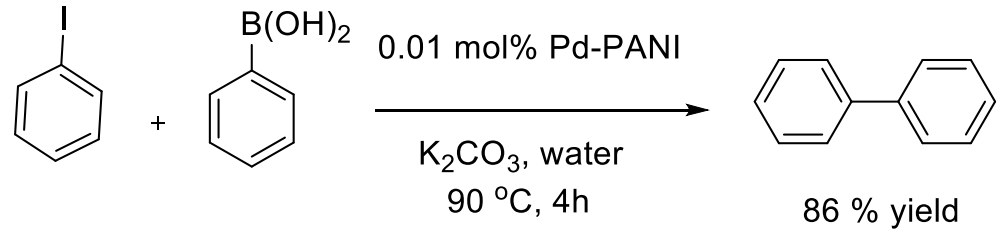

Scheme 44 Palladium-polyaniline nanocomposite for SMC in water.[82] 
Dipak and co-workers reported on the application of the modified Montmorillonite clay supported $\mathrm{Pd}(0)$-nanoparticles as an efficient catalyst for the SMC (Scheme 45).[83] This naturally occurring clay requires no surface functionalization and its pore sizes can be tuned by an acid activation. The modification of Montmorillonite clay was carried out by activating with $\mathrm{H}_{2} \mathrm{SO}_{4}$ under controlled conditions to generate nanopores on the surface, thus serving as a 'Host' for the $\operatorname{Pd}(0)$-nanoparticles. The supported $\operatorname{Pd}(0)$-nanoparticles were efficient catalysts for the SMC (up to 94\% yield) in water under ligand free conditions. The nano-catalyst could be recycled at least three consecutive runs with a little loss of catalytic activity.

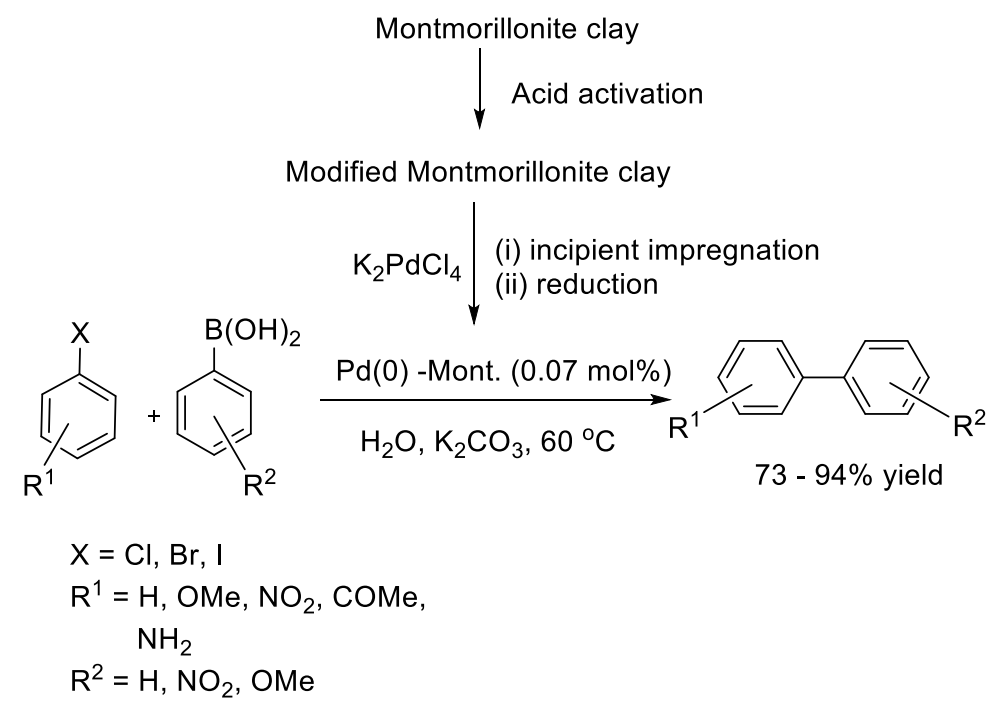

Scheme $45 \mathrm{Pd}(0)$-Montmorillonite clay composites catalyzed SMC in water.[83]

Recently, Li[84] reported on a highly dispersed palladium chloride catalyst anchored in triphenylphosphine-functionalized knitting aryl network polymers (KAPs) 64. These exhibited excellent activity for the SMC of aryl chlorides in aqueous media (Scheme 46). A potential reason for high catalyst activity was that the microporous 
polymers not only played the role of support, but also protected the $\operatorname{Pd}(0)$ species from aggregation and precipitation.

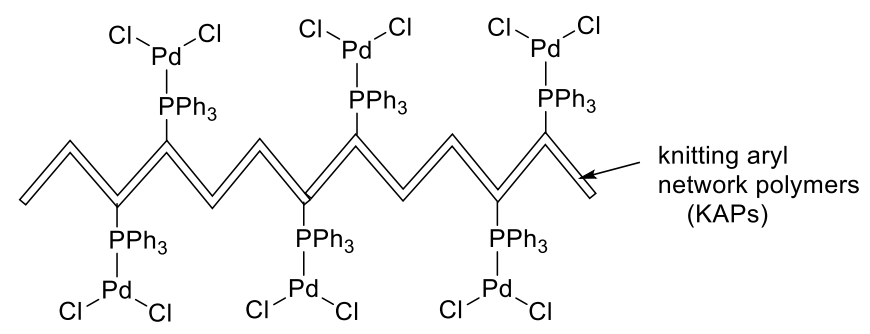

$\operatorname{KAPs}(\mathrm{Ph})-\mathrm{PPh}_{3}-\mathrm{Pd}$

64

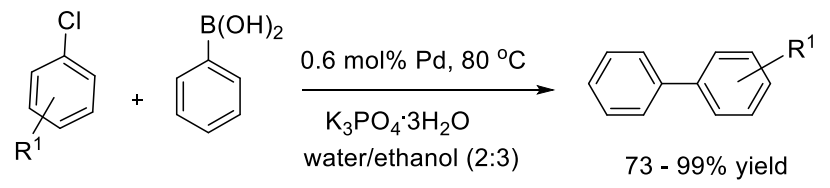

$\mathrm{R}^{1}=\mathrm{H}, \mathrm{COCH}_{3}$,

$\mathrm{NO}_{2}, \mathrm{CN}, \mathrm{Me}$

Scheme 46 Aqueous SMC catalyzed by KAPs(Ph-PPh $)-\mathrm{Pd} .[84]$

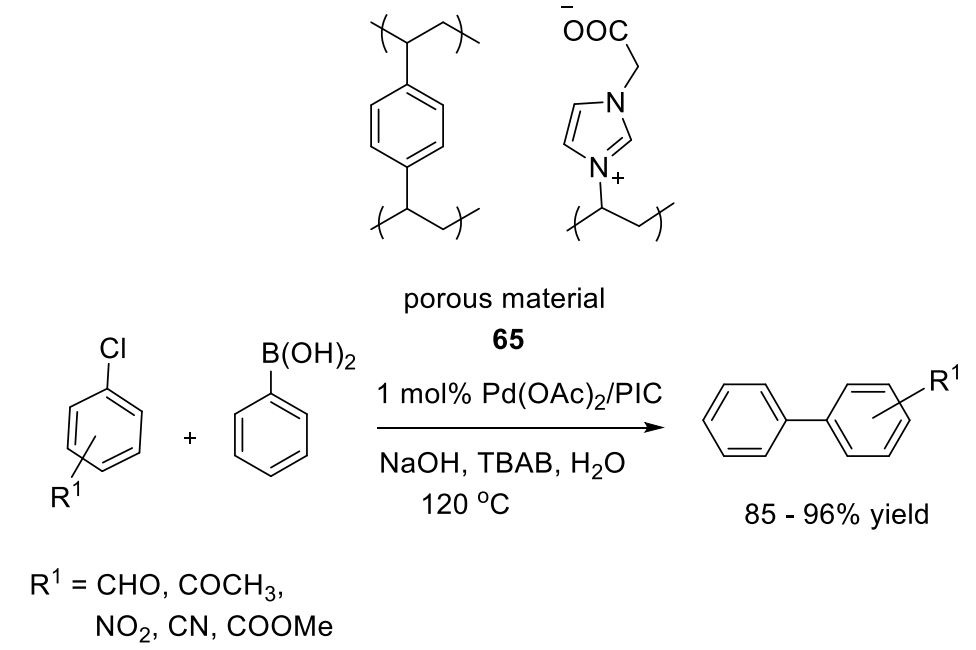

Scheme $47 \mathrm{~A} \mathrm{Pd}(\mathrm{OAc})_{2}$ /porous ionic copolymer (PIC) catalyzes the SMC in water.[85]

Huang and co-workers reported on the use of $\mathrm{Pd}$ nanoparticles on a porous ionic copolymer $\mathbf{6 5}$ of an ionic liquid and divinylbenzene for the coupling of aryl bromides 
and chlorides under air and in water, using Pd loadings as low as 10 ppm (Scheme 47).[85]

$\mathrm{Hu}$ and co-workers embedded Pd nanoparticles in carbon thin film-lined nanoreactors 67. The resulting embedded nanoparticles 68 catalyzed the SMC yielding good results, allowing the recycling of the heterogeneous catalyst (Scheme 48).[86] Thanks to their controllable size, composition and morphology, mesoporous silica (e.g. SBA-15 66) are highly attractive supports for immobilizing Pd nanoparticles.

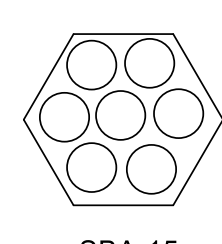

SBA-15

66
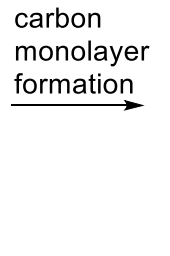
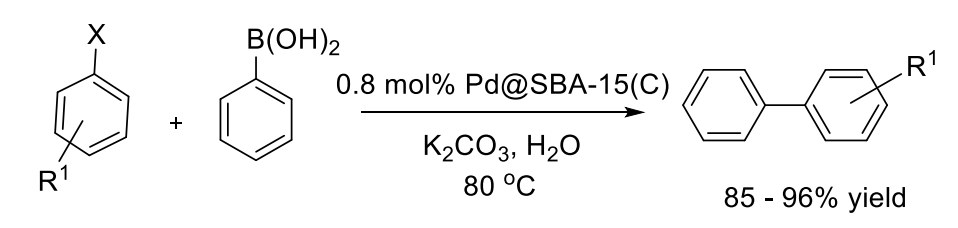

67

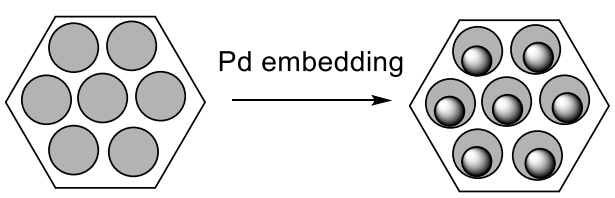

SBA-15(C)

67

Pd@SBA-15(C)

68

$\mathrm{X}=\mathrm{Cl}, \mathrm{Br}, \mathrm{I}$
$\mathrm{R}^{1}=\mathrm{H}, \mathrm{CHO}, \mathrm{COCH}_{3}$,
$\mathrm{NO}_{2}, \mathrm{COOMe}$

Scheme 48 Pd nanoparticles-embedded nanoreactor catalyzed SMC in water.[86]

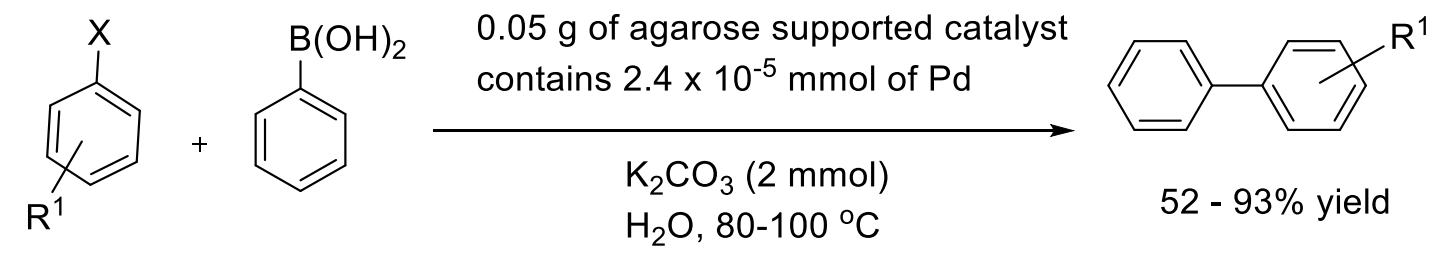

$\mathrm{X}=\mathrm{Cl}, \mathrm{Br}, \mathrm{I}$

$\mathrm{R}^{1}=\mathrm{H}, \mathrm{Me}, \mathrm{OMe}, \mathrm{COCH}_{3}$,

$\mathrm{NO}_{2}, \mathrm{OH}, \mathrm{CN}, \mathrm{Cl}, \mathrm{Py}$

Scheme 49 Agarose hydrogel supported Pd nano catalyst for the SMC in water.[87] 
Firouzabadi and Iranpoor used an agarose hydrogel to contain the Pd for the SMC in water (Scheme 49).[87] The catalyst was efficiently recycled five times.

Ma and Lei prepared a heterogenous biopolymer complex consisting of wool- $\mathrm{PdCl}_{2} \mathbf{6 9}$ that performed the SMC of aryl chlorides in water (Scheme 50).

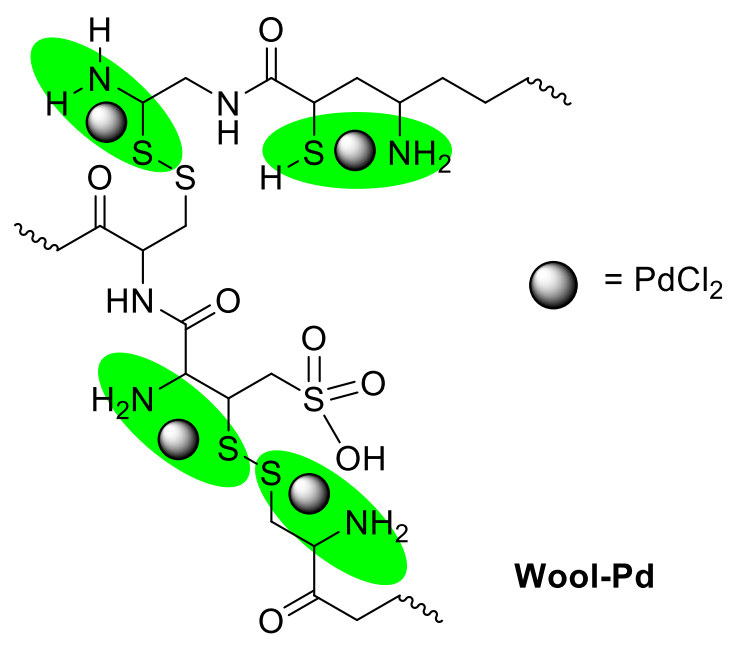

69

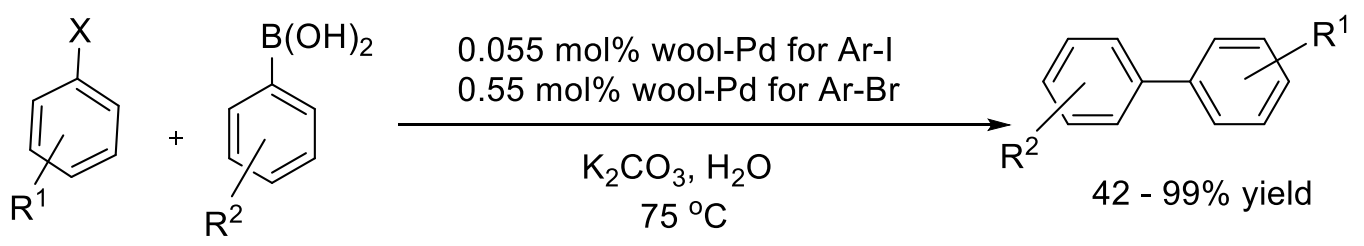

$\mathrm{X}=\mathrm{Br}, \mathrm{I}$ $\mathrm{R}_{2}=\mathrm{H}, \mathrm{OMe}$

$\mathrm{R}_{1}=\mathrm{H}, \mathrm{Me}, \mathrm{OMe}$

$\mathrm{COCH}_{3}, \mathrm{NO}_{2}, \mathrm{OH}$, $\mathrm{CN}, \mathrm{NH}_{2}, \mathrm{OEt}, \mathrm{CHO}$,

Py

Scheme 50 A wool-Pd complex the the SMC in water.[87]

$\mathrm{Li}$ and co-workers used recyclable monodispersed zeolithic hollow spheres $\mathbf{7 0}$ containing $\left.\left[\mathrm{PdCl}_{2} \text { (pyridine }\right)_{2}\right]$ to couple aryl bromides and iodides in a $60 \%$ aqueous ethanol solution (Scheme 51).[88] This catalyst afforded fast conversions for the SMC of various aryl halides and arylboronic acids even at Pd loadings of $0.0188 \mathrm{~mol} \%$. 
Under mild and aerobic conditions, a TOF $63210 \mathrm{~h}^{-1}$ is reported. This catalyst could be recycled at least 10 times without any loss of activity.
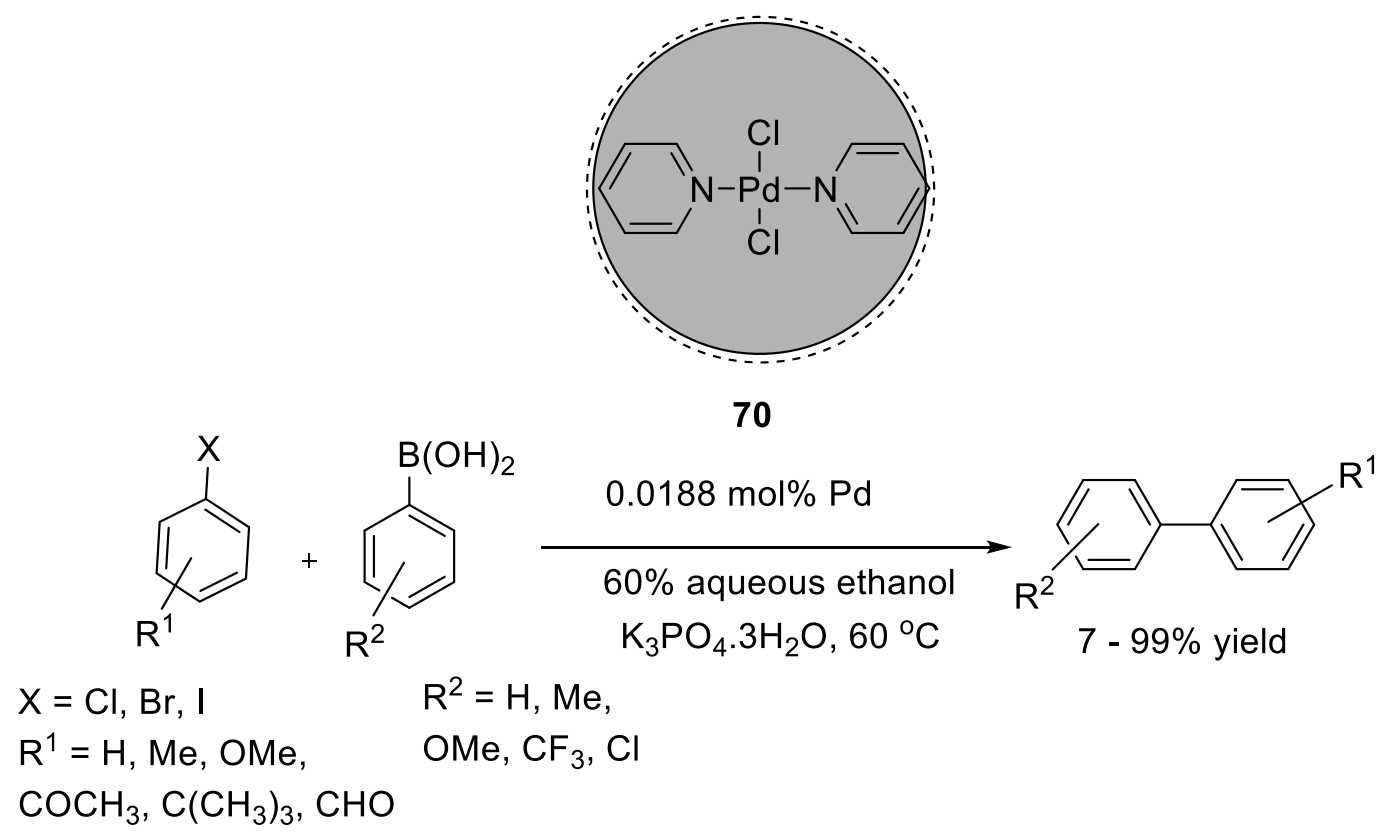

70

Scheme 51 Monodisperse zeolitic hollow spheres containing $\left[\mathrm{PdCl}_{2}(\text { pyridine })_{2}\right]$ catalyze the SMC in water.[88]

Yamada and Uozumi[89] developed a metalloenzyme-inspired polymer catalyst 71: a self-assembled catalyst consisting of poly(imidazole-acrylamide) and $\left[\left(\mathrm{NH}_{4}\right)_{2} \mathrm{PdCl}_{4}\right]$ that promoted the allylic arylation, alkenylation, and vinylation of allylic esters with aryl/alkenylboronic acids in water with TON varying between $20,000-1,250,000$ (Scheme 52). 


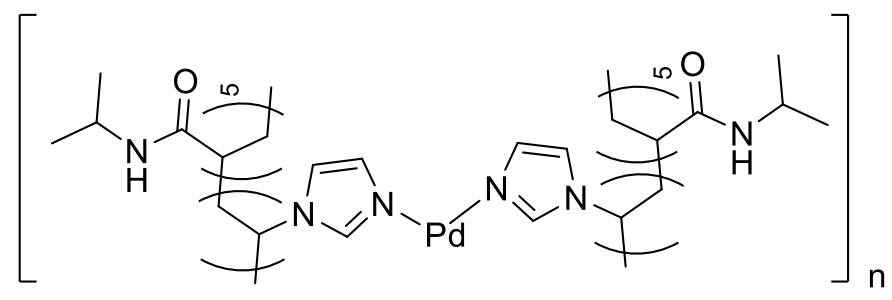

MEPI-Pd

71

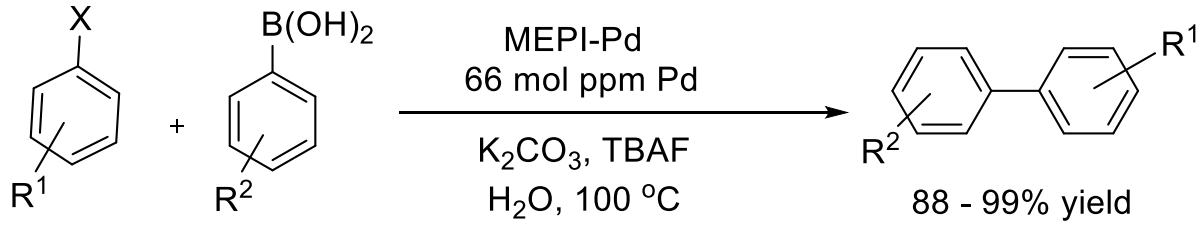

$\mathrm{X}=\mathrm{Cl}, \mathrm{Br}, \mathrm{I}$

$\mathrm{R}^{1}=\mathrm{Me}, \mathrm{CN}, \mathrm{COMe}$, $\mathrm{OH}, \mathrm{CN}, \mathrm{NH}_{2}$

$\mathrm{R}^{2}=\mathrm{H}, \mathrm{Me}, \mathrm{OMe}$

Scheme 52 A Metalloenzyme-inspired polymeric imidazole Pd catalyst (MEPI-Pd) for the SMC in water.[89]

\subsection{Unsupported catalyst}

In a recent study, Lipshutz and co-workers reported that nanoparticles formed from inexpensive $\mathrm{FeCl}_{3}$ that contains parts-per-million (ppm) levels of Pd catalyze the SMC in water (Scheme 53).[90] This system however requires the use of designer surfactant TPGS-750-M 72. This surfactant is composed of a lipophilic $\alpha$-tocopherol moiety and a hydrophilic PEG-750-M chain, joined by an inexpensive succinic acid linker, spontaneously forms micelles upon dissolution in water.

NHC-ligands are very common in homogeneous catalysis (vide supra), although they are rarely used in heterogeneous catalysis to stabilize $\operatorname{Pd}(0)$. Recently, Schmitzer used an unsupported Pd-NHC complex 73 for SMC (Scheme 54).[91] The catalyst is insoluble in water and the mercury drop test suggested the heterogeneity of the 
<smiles>COc1ccc(Br)cc1</smiles>

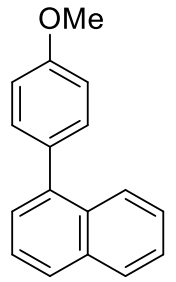<smiles>COCC(C)(C)OCC(C)(C)OC(=O)CCC(=O)Oc1c(C)c(C)c2c(c1C)CCC(C)(C(C)(C)CCCC(C)C)O2</smiles>

$98 \%$ yield

TPGS-750-M

72

Scheme $53 \mathrm{Fe}-$ ppm Pd nanoparticle catalyzed SMC in water.[90]

system. This heterogeneous catalyst was used in low loadings $\left(10^{-3} \mathrm{~mol} \%\right)$ for the SMC in pure water with very good recyclability $(10$ times) and high yield (TON = $\left.10^{5}\right)$
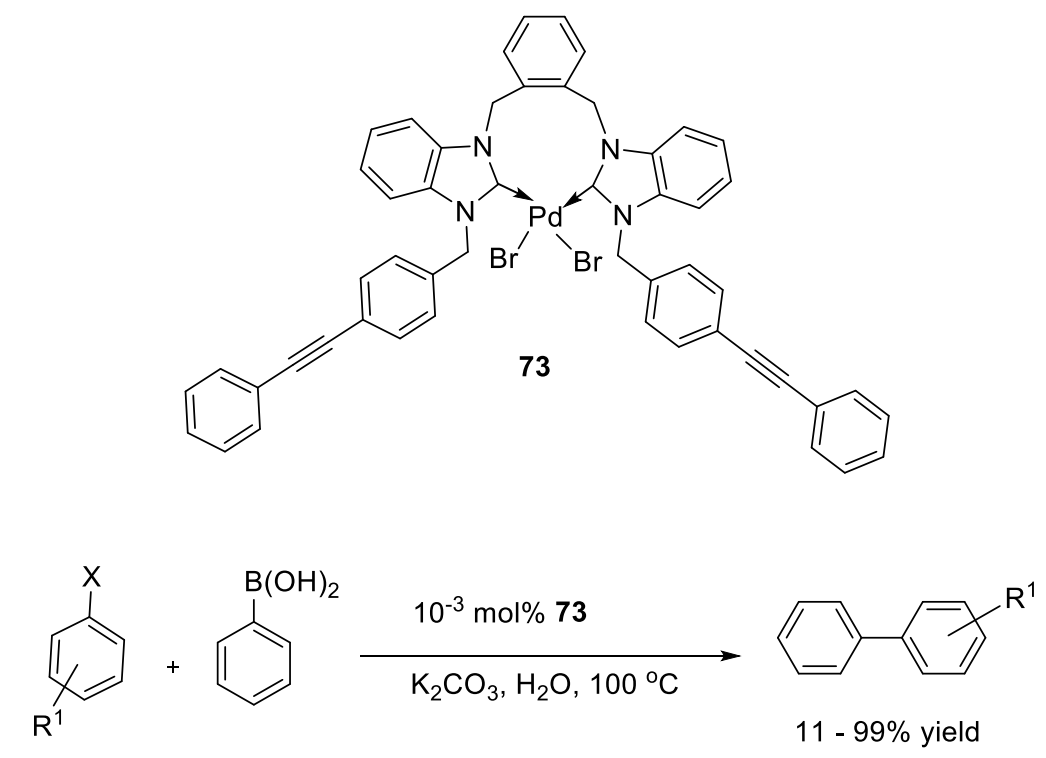

$\mathrm{X}=\mathrm{Cl}, \mathrm{Br}, \mathrm{I}$

$\mathrm{R}^{1}=\mathrm{H}, \mathrm{Me}, \mathrm{OMe}, \mathrm{CHO}$, $\mathrm{COCH}_{3}, \mathrm{NO}_{2}, \mathrm{NH}_{2}$

Scheme 54 Support-free palladium-NHC catalyst for SMC in water.[91] 
The first ligand-free SMC of aryl halides with potassium aryl-trifluoroborates in water was reported by Molander et al. in 2003.[92] Following this report, many groups developed ligand free strategies for SMC in water. In this context, Bora [93] and Liu $[94,95]$ have recently shown that the only use of $\mathrm{PdCl}_{2}$ and $\mathrm{Pd}(\mathrm{OAc})_{2}$, respectively, in the presence of an adequate base can couple a variety of aryl bromides in water. Boruah and co-workers reported $\mathrm{Pd}(\mathrm{OAc})_{2}$-catalyzed $\mathrm{SMC}$ of aryl bromides with arylboronic acids in aqueous tea extract at room temperature.[96] Recently, Corma and co-workers developed palladium clusters with three- or four palladium atoms (characterized by UV-visible spectroscopy) which were found to be the catalytically active species (3-300 ppm Pd, TOF up to $10^{5} \mathrm{~h}^{-1}$ ) for the SMC.[97] These palladium cluster could be stabilized in water and stored for long periods of time for use on demand with no loss of activity. Qiu and Xu reported Pd-Pt nanodendrites for a ligand free SMC in an ethanol-aqueous solution.[98] Liu and co-workers reported an aerobic, ligand-free SMC catalyzed by $\mathrm{Pd} / \mathrm{C}(3 \mathrm{~mol} \%)$ in aqueous media.[99] Control experiments demonstrated that the $\mathrm{Pd} / \mathrm{C}$-catalyzed the $\mathrm{SMC}$ was much quicker when performed in air or oxygen ( $98 \%$ yield in 30 minutes) than under nitrogen (62\% yield in 40 minutes). Deveau and coworkers[100] reported synthesis of Ethyl(4phenylphenyl)acetate, a biaryl with anti-arthritic potential using $\operatorname{Pd}(\mathrm{OAc})_{2}$ with no additional ligand in aqueous acetone ( $0.5 \mathrm{~mol} \%$ catalyst loading, $90 \%$ yield $)$. Liu and co-workers reported the SMC of potassium aryl-trifluoroborates with aryl bromides in water using $\mathrm{Pd}(\mathrm{OAc})_{2}$ as a catalyst (1-3 mol\%) with $\left[\mathrm{bmim}^{2} \mathrm{PF}_{6}\right.$ ionic liquid as an additive and $\mathrm{Na}_{2} \mathrm{CO}_{3}$ as a base under air.[101] They obtained biaryl products up to $99 \%$ yield in 2-3 hours. Sarma and Saikia reported recently a recyclable $\operatorname{Pd}(\mathrm{OAc})_{2}$ 
catalyzed SMC in neat "Water Extract of Rice Straw Ash" (WERSA) at room temperature.[102] They obtained $45-90 \%$ yield for the synthesis of biaryl product with $1 \mathrm{~mol} \%$ Pd loading.

Palladium nanoparticles (Pd-NPs) are nowadays widely used in catalysis and have become a strategic tool for organic transformations, thanks to their high catalytic activity. Pd-NPs are valuable alternatives to molecular catalysts as they do not require costly ligands. Astruc and co-workers showed that the SMC of aryl chloride proceeds efficiently in water (or in organic-water mixtures) at high temperatures with ppm amounts of Pd-NPs.[103]

Veisi and coworkers reported palladium nanoparticles (Pd-NPs) stabilised by Pistacia atlantica kurdica (P. a. kurdica) gum as catalyst for the SMC in water.[104] The PdNPs were employed as a heterogeneous catalyst in the SMC at low palladium loading (0.1 mol\%) under aerobic and ligand-free conditions in water. The system was characterized by moderate TONs (up to 980). The catalyst could be recycled at least eight times without loss of activity.

The group of Martin reported the synthesis of stable Pd-NPs generated by electrochemical methods at room temperature via the electroreduction of an aqueous solution of $\mathrm{H}_{2} \mathrm{PdCl}_{4}$ in the presence of PVP (xxx what is pvp).[105] These Pd-NPs exhibited high catalytic activity in the SMC in aqueous medium. Particularly high turnover numbers (TON $10^{4}-10^{5}$ ) were achieved with aryl iodides and bromides. Recently, Pore and co-workers reported ionic liquid promoted in situ generation of palladium nanoparticles (particle size between 3-9 $\mathrm{nm}$ ) which efficiently catalyzed 
SMC in water.[106] With $2 \mathrm{~mol} \% \mathrm{Pd}(\mathrm{OAc})_{2}$ and $20 \mathrm{~mol} \%$ ionic liquid, they achieved upto $98 \%$ yield at $80{ }^{\circ} \mathrm{C}$. The aqueous system containing ionic liquid along with PdNPs could be recycled seven times with any loss of activity. Maitra and co-workers reported hydrogel-stabilized palladium nanoparticles for SMC in water.[107] They obtained upto $90 \%$ yield for biaryl synthesis with $0.15 \mathrm{~mol} \%$ Pd loading. Recently Tang and co-workers reported Pd-NPs supported and stabilized by mesoporous graphitic carbon nitride $\left(\mathrm{g}-\mathrm{C}_{3} \mathrm{~N}_{4}\right)$. [108] The SMC proceeded smoothly with $97 \%$ isolated yield ( $0.83 \mathrm{~mol} \%$ Pd loading) in less than 30 minutes in water with PEG600 as the additive. Gholinejad and co-workers[109] reported a polymer containing phosphorus-nitrogen ligands for stabilization of palladium nanoparticles which was an efficient and recyclable catalyst for SMC in neat water. The biaryls products were obtained upto $99 \%$ yield with $0.08 \mathrm{~mol} \% \mathrm{Pd}$ loading in presence of ${ }^{t} \mathrm{BuOK}$ as a base. Liu and coworkers[110] developed a palladium-catalyzed ligand-free SMC of heteroaryl halides with $\mathrm{N}$-methyliminodiacetic acid (MIDA) boronates in excellent yields (up to 96\%) with $2 \mathrm{~mol} \%$ Pd loading.

\subsection{Heterogeneous SMC for Chemical Biology Applications}

The first use of the SMC in mammalian cells was reported by Bradley and coworkers.[56] They trapped palladium nanoparticles within inert polymeric microspheres, with the catalysts derived from a recyclable, ligand-free heterogeneous palladium precursor. The resulting polystyrene microspheres were employed as 'Trojan-horses' to deliver the palladium nanoparticles into a cell, allowing to perform a SMC of $\mathbf{7 4}$ and $\mathbf{7 5}$ to afford the fluorescent product $\mathbf{7 6}$ in cellulo (Scheme 55). [64, 
65] They used almost stoichiometric amount of catalyst and there is no mention of yield or TON in corresponding paper.

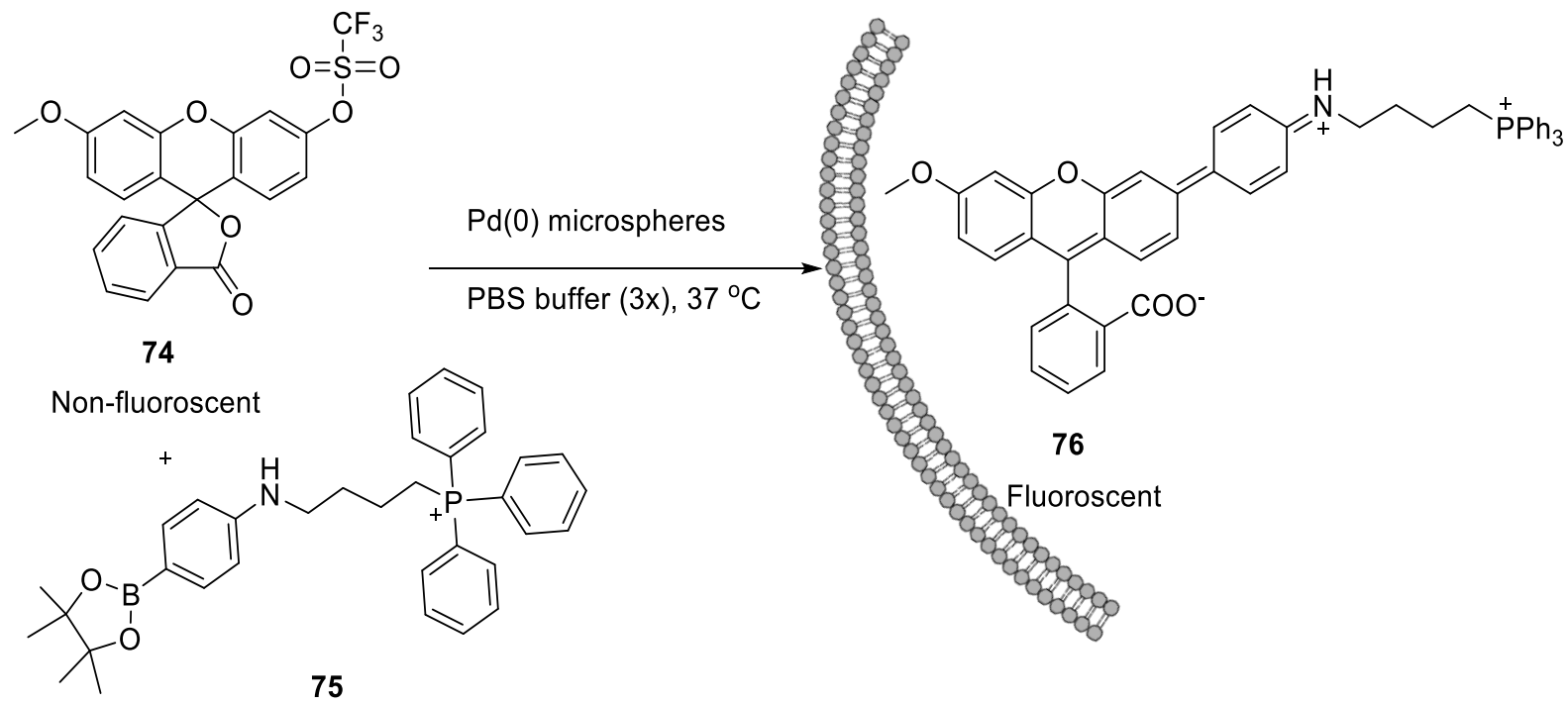

Scheme 55 Palladium nanoparticles encapsulated within inert polymeric microspheres as catalyst for the SMC in cellulo.[56]

The research group of Parker demonstrated that $\operatorname{Pd}(0)$-nanoparticles produced by living plants displayed excellent catalytic activity in the SMC.[66] Certain strains of bacteria (e.g. Desulfovibrio desulfuricans, E. coli and Shewanella oneidensis) can reduce soluble $\mathrm{Pd}(\mathrm{II})$ from stock solutions or acid extracts of spent catalysts, forming metallic palladium nanoparticles. This protocol involves biosorption of $\mathrm{Pd}(\mathrm{II})$ cations on the surface of bacteria and a subsequent reduction to $\operatorname{Pd}(0)$ using an electron donor. The formed nanoparticles are supported either on the bacterial outer-membrane or in the periplasmic space and remain attached to the cells ("bio-Pd(0)"). Skrydstrup and coworkers[69] reported that the SMC can be catalysed by bio-generated palladium nanoparticles formed on the surface of Gram-negative bacteria (Scheme 56). 


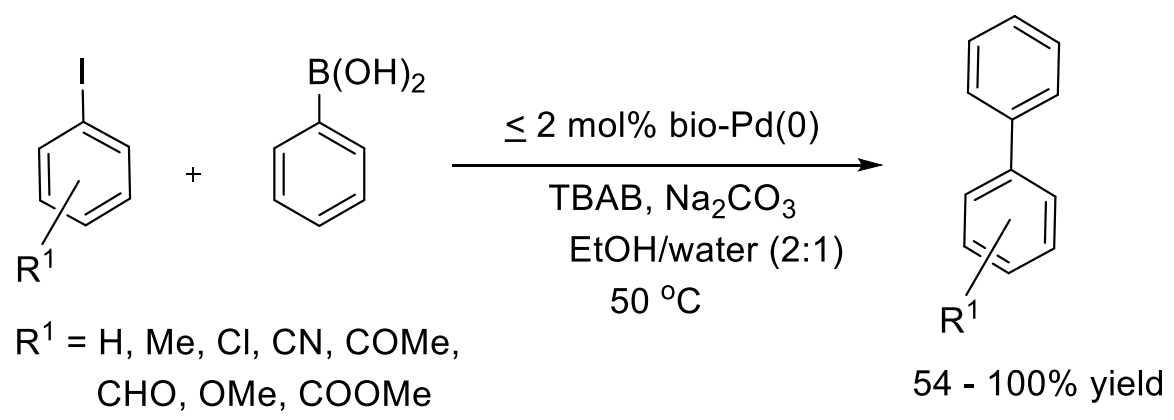

Scheme 56 "bio-Pd(0)" catalyzed SMC developed by Skrydstrup and coworkers.[69]

Biological macromolecules have gained significant attention as alternative template materials for the generation of well-dispersed metal nanoparticle via electroless deposition. Yi and coworkers[68] demonstrated that the tobacco mosaic virus (TMV) is a suitable support for the generation of immobilized palladium (Pd) nanocatalysts which are active for the SMC in water.

\section{Outlook}

In a green chemistry spirit, aqueous SMC has enjoyed an exponential growth in the past four years. In many cases however, the aqueous SMC require either high temperatures or the use of a co-solvent for chloride substrates. Future research will certainly be aimed to design more economical and high- performance catalysts.

\section{Acknowledgements}

\section{References}

1. Miyaura N, Suzuki A (1995) Chem Rev 95:2457

2. Suzuki A (2011) Angew Chem Int Ed 50:6722

3. Hassan J, Sévignon M, Gozzi C, et al. (2002) Chem Rev 102:1359

4. Littke AF, Fu GC (2002) Angew Chemie Int ed 41:4176 
5. Kotha S, Lahiri K, Kashinath D (2002) Tetrahedron 58:9633

6. Han F-S (2013) Chem Soc Rev 42:5270

7. Fihri A, Bouhrara M, Nekoueishahraki B, et al. (2011) Chem Soc Rev 40:5181

8. Maluenda I, Navarro O (2015) Molecules 20:7528

9. Li H, Johansson Seechurn CCC, Colacot TJ (2012) ACS Catal 2:1147

10. Kumar A, Rao GK, Kumar S, Singh AK (2013) Dalton Trans 42:5200

11. Rossi R, Bellina F, Lessi M (2012) Adv Synth Catal 354:1181

12. Sheldon RA (2012) Chem Soc Rev 41:1437

13. Simon M-O, Li C-J (2012) Chem Soc Rev 41:1415

14. Shaughnessy KH, DeVasher RB (2005) Curr Org Chem 9:585

15. Polshettiwar V, Decottignies A, Len C, Fihri A (2010) ChemSusChem 3:502

16. Sun Y, Yan M-Q, Liu Y, et al. (2015) RSC Adv 5:71437

17. Liu N, Liu C, Yan B, Jin Z (2011) Appl Organomet Chem 25:168

18. Mao S-L, Sun Y, Yu G-A, et al. (2012) Org Biomol Chem 10:9410

19. Marziale AN, Jantke D, Faul SH, et al. (2011) Green Chem 13:169

20. Burda E, Hummel W, Gröger H (2008) Angew Chem Int Ed 47:9551

21. Borchert S, Burda E, Schatz J, et al. (2012) J Mol Catal B Enzym 84:89

22. Lee J-Y, Ghosh D, Lee J-Y, et al. (2014) Organometallics 33:6481

23. Sabounchei SJ, Hosseinzadeh M, Panahimehr M, et al. (2015) Transit Met Chem 40:657

24. Togni A, Venanzi LM (1994) Angew Chemie 106:517

25. Tsang MY, Viñas C, Teixidor F, et al. (2014) Inorg Chem. doi: 10.1021/ic5013999 
26. Crisóstomo-Lucas C, Toscano RA, Morales-Morales D (2013) Tetrahedron Lett $54: 3116$

27. Tu T, Feng X, Wang Z, Liu X (2010) Dalton Trans 39:10598

28. Saikia B, Ali AA, Boruah PR, et al. (2015) New J Chem 39:2440

29. Zhou C, Wang J, Li L, et al. (2011) Green Chem 13:2100

30. Zhao C-W, Ma J-P, Liu Q-K, et al. (2013) Green Chem 15:3150

31. Hanhan ME, Senemoglu Y (2011) Transit Met Chem 37:109

32. Qi M, Tan PZ, Xue F, et al. (2015) RSC Adv 5:3590

33. Li Q, Zhang L-M, Bao J-J, et al. (2014) Appl Organomet Chem 28:861

34. Kapdi A, Gayakhe V, Sanghvi YS, et al. (2014) RSC Adv 4:17567

35. Chalker JM, Wood CSC, Davis BG (2009) J Am Chem Soc 131:16346

36. Edwards GA, Trafford MA, Hamilton AE, et al. (2014) J Org Chem 79:2094

37. Zhou Z, Liu M, Wu X, et al. (2013) Appl Organomet Chem. doi: 10.1002/aoc.3033

38. Zhang G, Zhang W, Luan Y, et al. (2015) Chinese J Chem. doi: $10.1002 /$ cjoc. 201500167

39. Mondal M, Bora U (2014) Tetrahedron Lett 55:3038

40. Liu H, Li X, Liu F, et al. (2015) J Organomet Chem 794:27

41. Arumugam V, Kaminsky W, Bhuvanesh NSP, Nallasamy D (2015) RSC Adv $5: 59428$

42. Lukowiak M, Meise M, Haag R (2014) Synlett 25:2161

43. Zhong R, Pöthig A, Feng Y, et al. (2014) Green Chem 4955. doi: 10.1039/C4GC00986J

44. Benhamou L, Besnard C, Kündig EP (2014) Organometallics 33:260

45. Garrido R, Hernández-Montes PS, Gordillo Á, et al. (2015) Organometallics $34: 15050$ 
46. Munz D, Allolio C, Meyer D, et al. (2015) J Organomet Chem. doi: 10.1016/j.jorganchem.2015.03.027

47. Li L, Wang J, Zhou C, et al. (2011) Green Chem 13:2071

48. Godoy F, Segarra C, Poyatos M, Peris E (2011) Organometallics 30:684

49. Izquierdo F, Corpet M, Nolan SP (2015) J Org Chem 2015:1920

50. Liu N, Liu C, Jin Z (2012) Green Chem 14:592

51. Karimi B, Akhavan PF (2011) Inorg Chem 50:6063

52. Karimi B, Fadavi Akhavan P (2011) Chem Commun 47:7686

53. Kolychev EL, Asachenko AF, Dzhevakov PB, et al. (2013) Dalton Trans $42: 6859$

54. Schmid TE, Jones DC, Songis O, et al. (2013) Dalton Trans 42:7345

55. Kinzhalov MA, Luzyanin K V., Boyarskiy VP, et al. (2013) Organometallics $32: 5212$

56. Yusop RM, Unciti-Broceta A, Johansson EM V, et al. (2011) Nat Chem 3:239

57. Abe S, Niemeyer J, Abe M, et al. (2008) J Am Chem Soc 130:10512

58. Li J, Chen PR (2012) Chembiochem 13:1728

59. Gao Z, Gouverneur V, Davis BG (2013) J Am Chem Soc 135:13612

60. Spicer CD, Triemer T, Davis BG (2012) J Am Chem Soc 134:800

61. Li N, Lim RK V, Edwardraja S, Lin Q (2011) J Am Chem Soc 133:15316

62. Gao Z, Gouverneur V, Davis BG (2013) J Am Chem Soc 135:13612

63. Spicer CD, Davis BG (2011) Chem Commun 47:1698

64. Chankeshwara S V, Indrigo E, Bradley M (2014) Curr Opin Chem Biol 21:128

65. Unciti-Broceta A, Johansson EM V, Yusop RM, et al. (2012) Nat Protoc 7:1207

66. Parker HL, Rylott EL, Hunt AJ, et al. (2014) PLoS One 9:e87192 
67. Ma X, Wang H, Chen W (2014) J Org Chem 79:8652

68. Yang C, Manocchi AK, Lee B, Yi H (2011) J Mater Chem 21:187

69. Søbjerg LS, Gauthier D, Lindhardt AT, et al. (2009) Green Chem 11:2041

70. Yang M, Li J, Chen PR (2014) Chem Soc Rev 43:6511

71. Cobo I, Matheu MI, Castillón S, et al. (2012) Org Lett 14:1728

72. Dumas A, Spicer CD, Gao Z, et al. (2013) Angew Chem Int Ed 52:3916

73. Spicer CD, Davis BG (2013) Chem Commun 49:2747

74. Isfahani AL, Mohammadpoor-Baltork I, Mirkhani V, et al. (2013) Adv Synth Catal 355:957

75. Wang D, Liu W, Bian F, Yu W (2015) New J Chem 39:2052

76. Gholinejad M, Razeghi M, Najera C (2015) RSC Adv 5:49568

77. Karimi B, Mansouri F, Vali H (2014) Green Chem 16:2587

78. Zhang F, Chen M, Wu X, et al. (2014) J Mater Chem A 2:484

79. Mieczyńska E, Borkowski T, Cypryk M, et al. (2014) Appl Catal A Gen 470:24

80. Liu H, Wang P, Yang H, et al. (2015) New J Chem 39:4343

81. Liu M, Zhu X, Wu L, et al. (2015) RSC Adv 5:38264

82. Dutt S, Kumar R, Siril PF (2015) RSC Adv 5:33786

83. Borah BJ, Borah SJ, Saikia K, Dutta DK (2014) Appl Catal A Gen 469:350

84. Li B, Guan Z, Wang W, et al. (2012) Adv Mater 24:3390

85. Yu Y, Hu T, Chen X, et al. (2011) Chem Commun 47:3592

86. Zhi J, Song D, Li Z, et al. (2011) Chem Commun 47:10707

87. Firouzabadi H, Iranpoor N, Gholinejad M, Kazemi F (2011) RSC Adv 1:1013

88. Guan Z, Hu J, Gu Y, et al. (2012) Green Chem 14:1964 
89. Yamada YMA, Sarkar SM, Uozumi Y (2012) J Am Chem Soc 134:3190

90. Handa S, Wang Y, Gallou F, Lipshutz BH (2015) Science 349:1087

91. Charbonneau M, Addoumieh G, Oguadinma P, Schmitzer AR (2014) Organometallics 33:6544

92. Molander GA, Biolatto B (2003) J Org Chem 68:4302

93. Mondal M, Bora U (2012) Green Chem 14:1873

94. Liu C, Zhang Y, Liu N, Qiu J (2012) Green Chem 14:2999

95. Liu C, Rao X, Song X, et al. (2013) RSC Adv 3:526

96. Goswami L, Gogoi P, Gogoi J, et al. (2014) Tetrahedron Lett 55:5539

97. Leyva-Pérez A, Oliver-Meseguer J, Rubio-Marqués P, Corma A (2013) Angew Chem Int Ed 52:11554

98. Wang Z-J, Lv J-J, Feng J-J, et al. (2015) RSC Adv 5:28467

99. Liu C, Rao X, Zhang Y, et al. (2013) J Org Chem 2013:4345

100. Costa NE, Pelotte AL, Simard JM, et al. (2012) J Chem Educ 89:1064

101. Liu L, Dong Y, Pang B, Ma J (2014) J Org Chem 79:7193

102. Boruah PR, Ali AA, Chetia M, et al. (2015) Chem Commun 51:11489

103. Deraedt C, Astruc D (2014) Acc Chem Res 47:494

104. Veisi H, Faraji AR, Hemmati S, Gil A (2015) Appl Organomet Chem 29:517

105. Uberman PM, Pérez LA, Martín SE, Lacconi GI (2014) RSC Adv 4:12330

106. Patil JD, Korade SN, Patil SA, et al. (2015) RSC Adv. doi: 10.1039/C5RA17186E

107. Maity M, Maitra U (2014) J Mater Chem A 2:18952

108. Zhao Y, Tang R, Huang R (2015) Catal Letters. doi: 10.1007/s10562-015-1600$\mathrm{x}$

109. Gholinejad M, Hamed F, Biji P (2015) Dalton Trans 44:14293 
110. Liu C, Li X, Liu C, et al. (2015) RSC Adv 5:54312 